\title{
It Worked There, So It Should Work Here: Sustaining Change while Improving Product Development Processes
}

\author{
Shawn T. Collins (corresponding author) \\ Dept. of Technology Leadership and Communication \\ Indiana University-Purdue University, \\ Indianapolis, IN 46202 \\ shawn.collins@alumni.purdue.edu \\ Tyson R. Browning \\ Dept. of Information Systems and Supply Chain Management \\ Neeley School of Business \\ Texas Christian University \\ TCU Box 298530, Fort Worth, TX 76129 \\ t.browning@tcu.edu
}

\begin{abstract}
Acknowledgements
The authors would like to thank the many reviewers and editors whose comments helped to improve this paper considerably during the review process. The second author is grateful for research support from a Neeley School of Business Research Excellence Award at Texas Christian University. The research data for this paper were collected while the first author was a doctoral student at the University of Connecticut. The paper reflects the opinions of the authors, and not their affiliated institutions, DevCo, or MultiNat.
\end{abstract}

This is the author's manuscript of the article published in final edited form as:

Collins, S. T., \& Browning, T. R. (2019). It worked there, so it should work here: Sustaining change while improving product development processes. Journal of Operations Management, 65(3), 216-241. https://doi.org/10.1002/joom.1010 


\begin{abstract}
Organizations operate under ongoing pressure to conduct product development (PD) in ways that reduce errors, improve product designs, and increase speed and efficiency. Often, managers are expected to respond to this pressure by implementing process improvement programs (PIPs) based on best practices elsewhere (e.g., in another part of their organization or in another industrial context). Successful PIP implementation depends on two criteria: (1) demonstrating (symbolic) success by meeting externally imposed deadlines and producing mandated artefacts and (2) sustaining the expected (substantive) changes in their employees' underlying beliefs and practices. Given the mixed success of PIPs in non-manufacturing contexts, identifying factors that contribute to both symbolic and substantive implementation is important to both researchers and practitioners. We explore this challenge through an in-depth field study at a PD company (DevCo) that implemented a PIP across its 11 PD projects. We examine DevCo's change message to implement the PIP, how DevCo's engineers experienced it, factors that impeded implementation, and factors that could improve substantive success. Along with this empirical evidence, we leverage organizational change concepts to facilitate effective PIP implementation in new contexts such as PD. We distill our findings into eight propositions that expand theory about effectively transferring PIPs across contexts.
\end{abstract}

Keywords: Process improvement, Organizational change, Product development, Clinical research 


\section{Introduction}

Process improvement programs (PIPs) are organizational initiatives intended to improve the efficiency, effectiveness, and consistency of work - such as improving product designs, reducing errors, and decreasing requirements for time, money, and other resources. Given constant pressure for better results in their organizations, PIPs are a fact of life for many managers in a variety of contexts, such as manufacturing, service operations, healthcare, and product development (PD) (Linderman et al. (2003); Schroeder et al. (2008); Zu et al. (2008)). Practitioners make substantial investments in PIPs (e.g., Lean, Six Sigma, Agile and Scrum) to transfer existing ones across national cultures (e.g., implementing Japanese manufacturing practices in US assembly plants) and functional or operational domains (e.g., applying Lean or Six Sigma in service operations, healthcare, and PD). Many claim that PIP principles and best practices are generic and thus transferable across contexts (Browning and Heath, 2009).

Despite such claims, the desired benefits of PIPs are inconsistently realized in practice (Arlbjørn and Vagn Freytag, 2013; Hackman and Wageman, 1995; Hines et al., 2004; Jadhav et al., 2014; Repenning, 2000; Staats et al., 2011; Swink and Jacobs, 2012; Victor et al., 2000). According to Netland (2016), two out of every three change initiatives do not achieve their desired results, only one in four manufacturing plants that employed Lean production in the US was satisfied with the results, and many organizations struggle to sustain momentum beyond initial implementation of their Lean practices. (Findings by Danese et al. (2017), that Lean requires similar efforts to sustain as it does to implement, echo the previous statement.) These findings highlight a non-trivial challenge for the operations management (OM) community. Numerous PIP practices exist with evidence that they (occasionally) work. Furthermore, managers are expected to implement those practices, under the premise that what worked in one place will bring the same positive results elsewhere. However, few have studied the question of how to reliably implement PIPs when the principles are applied in new contexts (an issue noted by Lillrank (1995) and explored by Staats et al. (2011)).

This paper seeks to improve our understanding of such situations in three ways that are relevant to OM theory and practice. First, this paper addresses PIP implementation that is mandatory instead of voluntary. When a PIP is successfully implemented elsewhere, a manager may be expected to implement the same practices in their own organization. The priority is often for the manager to mobilize resources within his or her organization in order to comply with the imposed expectations (symbolic success). Such expectations often leave managers with limited flexibility for their employees to develop solutions that address their specific operational challenges and embed sustainably altered behaviors (substantive success). It is possible, as in the case of Six Sigma at 3M, for a mandatory PIP to evolve over time in ways that increase its substantive success (Canato and Ravasi, 2014; Canato et al., 2013). However, both scholars and practitioners should understand how to proactively evolve a mandatory PIP implementation. Improved 
understanding of how these situations affect PIPs in practice is crucial for building sound theory (Handfield and Melnyk, 1998; Langley et al., 2013) and helping organizations to navigate the landscape of externally imposed mandates.

Second, our understanding of what PIPs are exceeds our understanding of how to implement them (e.g., Anand et al., 2010; Black and Porter, 1996; Jones et al., 2010; Schroeder et al., 2005; Zhang et al., 2011). In the presence of expectations to replicate PIP best practices that "worked there," many organizations implement PIPs without substantively changing their employees' underlying patterns of action: They espouse change without verifying that they have actually achieved it (Hackman and Wageman, 1995; Pentland and Feldman, 2008; Zbaracki, 1998). When this happens, they implement a PIP without a solid understanding of the causal paths from metrics to desired behavioral outcomes (Melnyk et al., 2010) or potential sources of variation as PIP practices diffuse into their organizations (Ansari et al., 2010).

Third, OM researchers and practitioners must articulate the characteristics and underlying causal factors of a successful PIP across multiple contexts. This is important when organizations seek to expand on successful PIP experiences by replicating them elsewhere (Danese et al., 2017; Lillrank, 1995). Many organizations use PIPs to characterize and control technical knowledge (Bohn, 1994) across the entire product lifecycle, thus extending their scope upstream from standardized production to the innovation work of designing and developing new products and services (Browning and Sanders, 2012; Davenport et al., 1996; McManus et al., 2007; Murman et al., 2002; Staats et al., 2011).

We combine empirical evidence from a 24-month, in-depth, clinical research study (Schein, 1987, 1993) at a PD company (DevCo) with multiple streams of literature-including process improvement, organizational change, and organizational behavior - to expand theory about transferring PIPs and sustaining their implementation. Our research was problem-solving-oriented (LaGanga, 2011; Lok and De Rond, 2013; Mathieu, 2016; Staats et al., 2011; Van Oorschot et al., 2013) in that we examined part of DevCo's "system health" (Schein, 1987:40) in terms of how effectively it implemented a PIP across the 11 PD projects in its Engineering department. DevCo's PIP implementation experienced gaps between its symbolic and substantive success (Hackman and Wageman, 1995; Sousa and Voss, 2002, 2008) and thus failed to achieve the desired outcome of sustained implementation. By exploring DevCo's PIP implementation in light of existing theory about organizational change, we contribute to OM theory (Ketokivi and Choi, 2014) about successfully transferring PIPs to new contexts.

We explore relationships between (1) the priorities of the PIP's steering committee (who defined its principles and practices) and DevCo's senior leadership (who defined the change message) and (2) the dynamics of DevCo's working-level engineers (who responded to the PIP). We identify three internal factors - conflicting environmental interpretations, inadequate PIP tools, and problematic metaphors - that reduced the efficacy of DevCo's PIP implementation, thereby limiting the desired outcome of new, shared 
beliefs and behaviors in the Engineering department. We also identify three negative factors - distant benefits, empty milestone compliance, and overreliance on grassroots adoption - that increased the gap between symbolic and substantive change. Finally, we identify two positive factors-flexible routines and tailored principles - that shift focus away from off-the-shelf practices ("It worked there, so do it here") toward contextualization of underlying principles - thereby enhancing the flow of value-added information within a PD context and reducing the gap between symbolic and substantive change. We use our findings to develop eight propositions that reconceptualize existing $\mathrm{OM}$ and organizational change constructs (Colquitt and Zapata-Phelan, 2007) and guide both the research and practice of effective PIP implementation in new contexts such as PD.

\section{Background and Initial Framework}

\subsection{Transferring PIPs to PD: Challenges of Context and Mandatory Implementation}

According to the "thesis of transference" (Womack et al., 1990), operations managers in diverse contexts share a common set of problems. Hence, they should also be able to share a common set of solutions to those problems. The assertion is that PIP principles and practices (e.g., Lean's principles of specifying value, identifying the value stream, making value flow continuously, letting the customer pull value, and pursuing perfection (Womack and Jones, 2003) and Six Sigma's problem-solving method, role structure, and use of specific metrics (Schroeder et al., 2008)) can be transferred across contexts to increase efficiency and effectiveness. Many consider PIPs to be generic enough to apply across the entire product lifecycle, encompassing both the knowledge work associated with developing new products and the production work associated with manufacturing and supporting them in service (e.g., McManus et al., 2007; Oppenheim, 2004).

PIPs are part of the broader area of management innovation, which introduces new practices, processes, or structures to further organizational goals (Volberda et al., 2014). PIP transfer is the adoption of external practices, which may be adapted for the specific context or expected to work "off the shelf." The transfer takes place within a specific organizational power structure. A successful PIP implementation can create expectations that the same practices will work again, elsewhere (Canato and Ravasi, 2014; Canato et al., 2013; Danese et al., 2017; Lillrank, 1995). Hence, managers are often directed to implement specific practices by prescribed deadlines with expectations of success. These expectations limit managers' flexibility to allow their employees to contextualize solutions for specific situations and challenges. Rather, managers must mobilize resources within their organization to comply with the imposed expectations.

Transferability, while appealing in principle, has proven to be challenging in practice. The OM literature reports many successful implementations of PIP principles in various contexts, but also reasons why different contexts challenge some of the basic assumptions of those PIP principles in ways that compromise effective implementation (Danese et al., 2017; Groop et al., 2017; Lillrank, 2003; Szulanski, 
1996, 2000; Yin et al., 2017). For example, Lean gained a foothold in American manufacturing companies only after data emerged to demonstrate that American companies could implement practices previously considered unique to Japanese culture (Holweg, 2007). Yet, reliable transferability of PIPs is open to question, especially in the context of more novel and complex project work such as PD, where the point is to design something new, once-not reproduce it repeatedly (Browning, 2003; Browning and Sanders, 2012). The inputs, transformations, and outputs (i.e., activities and processes) associated with PD activities involve acquiring, processing, and transferring new information and knowledge (Browning and Heath, 2009).

This "knowledge work" context poses several differences for PIP implementation in comparison to manufacturing contexts (Browning et al., 2006; Staats et al., 2011). First, the PD context is more uncertain and unstable. Often, customers cannot perfectly define their requirements and preferences (sources of value) before PD begins. Organizations must forecast requirements and interact with their customers frequently to define their work correctly. This may happen amid changes to their product and process technologies and external environment. Second, PD activities have higher degrees of uncertainty. The partial visibility of relationships among activities often limits a worker's ability to identify and resolve emerging problems. PD process variability is high: It is often possible to perform various activities without all of their ideal inputs by using assumptions instead. Whereas activities such as testing and rework are considered waste in traditional lean implementations, they can add value to PD efforts by reducing uncertainty and risks to value (Browning, 2003). Third, the high-level product architecture evolves as requirements, technological capabilities, and external environment all become better defined. This means that PD activities are conducted amidst high levels of architectural ambiguity. It is akin to repeatedly executing individual manufacturing processes while simultaneously redesigning the assembly process.

These characteristics of information flow in PD contexts have been identified in the OM literature, leading to new approaches for framing and tailoring project management for PD contexts (e.g., Chandrasekaran et al., 2015; Pich et al., 2002). They remain a contextual challenge for PIP transferability that has not been well explored. Organizations seeking to transfer PIP principles to PD contexts must reconceptualize key variables such as waste and value so that the design management activities in PD can be effectively targeted for process improvement (Ahire and Dreyfus, 2000; Browning, 2003; Lillrank, 1995). The application of PIP tools to PD must amplify creativity in high-uncertainty conditions by enhancing the flow of value-adding information (Eidt, 1992; Spain, 1996) and the execution of business strategies intended to encourage innovation (Adler et al., 2009; Browning and Sanders, 2012; Choo et al., 2007; Johnson and Swisher, 2003). Thus, while problems of waste and productivity exist in all operational contexts, it is not yet clear how to sustainably implement PIP principles in ways that address the challenges of improving knowledge-embedding processes and contextually dependent problem-solving techniques 
(instead of abstract rules). In this paper, we explore one firm's attempt to transfer a PIP from a production context to PD, observing details of implementation to contribute to the "roadmap for knowledge-based industries seeking to apply the same ideas" (Staats et al., 2011).

\subsection{Transferring PIPs to PD: The Challenge of Achieving Substantive Change}

PIPs are process innovations (Damanpour, 2001) that introduce new elements into an organization's operations by enabling employees to continuously improve their activities. PIPs are thus expected to cause cultural changes. However, limited research exists to understand the actual process by which PIPs create behavioral changes (e.g., Birkinshaw et al., 2008; Volberda et al., 2014). Indeed, the scholarly literature suggests that many firms implement PIPs without substantively changing their employees' underlying patterns of action (Hackman and Wageman, 1995; Pentland and Feldman, 2008; Zbaracki, 1998). Both scholars and practitioners frequently cite human behavior as a primary reason that PIPs fail to achieve their intended results (Baba, 1995; Dahlgaard and Dahlgaard-Park, 2006; Hackman and Wageman, 1995; Liker et al., 1999; Linderman et al., 2004; Zu et al., 2009). For example, Beer (2003) attributed Total Quality Management (TQM) failures to poor implementation (top management did not exhibit the behaviors required to create the culture change that would enable sustained benefits from the TQM initiative) rather than flaws in the underlying theory or method. Bhakoo and Choi (2013) noted that implementation of interorganizational systems across healthcare supply chains can be ceremonially successful without impacting the technical core of an organization. As such, a key aspect of PIP effectiveness depends on the human behavior that develops in response to their implementation.

Substantively changing underlying behavior patterns presents an organizational challenge for implementing PIPs, especially in PD environments. It is known that (a) introducing a PIP requires nontrivial changes in organizational operations, and (b) a lack of change will hinder or halt effective PIP implementation in a known context such as manufacturing (Browning and Heath, 2009; Holweg, 2007). It is not yet known how organizations seeking to implement PIPs can most effectively garner support from diverse individuals and social systems to drive and sustain the PIP's associated beliefs and behaviors (Henderson et al., 1998; Kull et al., 2012; Zmud, 1984).

\subsection{Initial Framework: PIP Implementation as Organizational Change}

As stated in the Introduction, scholarly understanding of how to implement PIPs lags the description of what they are. In recent years, research on PIP implementation has progressed in two areas. The first area concerns the behavioral challenges associated with PIP implementation in production environments (e.g., Furterera and Elshennawy, 2005; Naor et al., 2008; Pisani et al., 2009) and the coordination of PIP practices and tools with supporting infrastructure to change organizational routines (Linderman et al., 2010). The second area concerns how to define characteristics of PIPs in new contexts. Beyond simply stating that PIP principles are transferrable, this stream seeks to rearticulate PIP principles for new contexts (e.g., Browning, 
2003; Browning and Heath, 2009; Poppendieck and Poppendieck, 2003). These two areas of research have improved our understanding about (1) how to implement PIPs in ways that increase substantive change in contexts where PIP applications already have a mature history and (2) how to reconceptualize PIP principles in new contexts, respectively. Yet, only limited research (e.g., Lillrank, 1995; Staats et al., 2011) has addressed both areas at once, as this paper does.

Following Armenakis and colleagues (Armenakis and Harris, 2002; Rafferty et al., 2012), we draw upon Lewin's (1951) three-phase change sequence of unfreezing (readiness), changing (adoption), and refreezing (institutionalization) to suggest a framework for addressing this challenge. Lewin's sequence serves as both an explicit and tacit framework for contemporary research on organizational change - e.g., leading change (Kotter, 1996), dealing with middle managers (Huy, 2001), issue-selling (Dutton et al., 2001), grassroots change (Frohman, 1997), and ensuring that changes address the right problem (e.g., Kilmann and Mitroff, 1979). In addition to providing a framework for change implementation, the sequence also emphasizes the need to understand the interaction between the change message, the organization being changed, and the organization's environment (e.g., Jiao and Zhao, 2014). This acknowledges the challenge of transferability (although Lewin and others did not use the term explicitly). Hence we suggest that Lewin's sequence is helpful for understanding the implementation of PIPs in unconventional contexts such as PD. In this paper, we use it to examine PIP implementation as a type of organizational change.

Our initial framework operationalizes an effective organizational change as one that progresses through all three of Lewin's phases (recognizing that actual progression through the phases is interactive and not as linear as described here), whereas not doing so will reduce the change's effectiveness. We do not define PIP effectiveness based on meeting organizational milestones, because, as stated in Section 1, symbolic success does not verify substantive underlying change. Also, although it would be useful to do so in future research, we do not define PIP effectiveness in terms of time or money, because many confounding factors can affect these results. For example, PD managers could attain short-term efficiency gains by simply eliminating activities, which could compromise long-term effectiveness. Instead, drawing from work by Schein (1996) and Armenakis and colleagues (Armenakis and Harris, 2002; Armenakis et al., 1993), we assess effective PIP implementation based on the presence of behavioral characteristics that impact the efficacy of each phase in Lewin's sequence. We relate each phase in Lewin's sequence to existing theory and deeper principles that guide and evaluate change implementations.

Lewin's first phase, unfreezing, creates readiness to change by reducing the strength of forces that maintain the status quo and increasing the strength of forces for change. This occurs by creating urgency (confirming that the organization accepts the need for a change) and communicating a clear discrepancy between the current condition and the desired future state. This phase is where PIP principles are articulated for the new context (e.g., PD) in a manner that demonstrates the value of adopting them. Lewin's second 
phase, change, involves actually adopting new ways of working. This requires demonstrating that the change is an appropriate solution to the problem identified during the unfreezing phase. According to Armenakis and Harris (2002), this is a trial phase after which employees may still choose to reject the proposed change. The third phase, refreezing, is needed to institutionalize the change and ensure that the forces are sufficiently strong to maintain the new status quo. This requires providing necessary resources (training, personnel, and funding) to support the change effort and demonstrating direct benefits. ${ }^{1}$ for individuals who adopt the change. In terms of PIP implementation, this last phase is where the PIP's principles are embedded in the new context (e.g., PD) and ensured to be sustainable. Overall, we sought to explore each of these aspects in relation to the effectiveness of PIP implementation.

\section{Research Setting and Methods}

We collected data over 24 months in 2005-06 as part of a larger, mixed-methods ethnographic study (Handwerker, 2001), examining expertise and process control in DevCo's Engineering department (Collins, 2009; Collins et al., 2010; Collins et al., 2009). Our interest in transferring PIP principles from manufacturing to PD contexts, with the associated burden of organizational change, led us to adopt a clinical study methodology (e.g., Barley and Kunda, 2001; Coghlan, 2009; Howard-Grenville, 2005; Schein, 1987, 1993) that sought to understand how the PIP conceptualized improvement relative to daily practices at DevCo and how the PIP implementation was managed as an organizational change initiative. Clinical research is well positioned to study these issues because it captures the operation of power and authority, the role of "perceptual defenses," the interactions and linkages of "forces across hierarchical boundaries," and the dynamic nature of those forces as the situation changes (Schein, 1993:705). These data identify psychological defenses and cultural assumptions that "do not reveal themselves easily to uninvolved observers, surveyors, testers, or experimenters" (Schein, 1993) and that are often identified as contributing to the unsuccessful implementation of PIPs (e.g., Beer, 2003). DevCo's PIP implementation was a case in which such processes were "transparently observable" (Eisenhardt, 1989) and "contextually rich" (Bhakoo and Choi, 2013). The in-depth observations across organizational power levels allowed for the uncovering of phenomena pertaining to the transfer of PIPs to PD contexts. This enabled us to observe and describe complicated research phenomena in ways that increased our understanding of the landscape (Eisenhardt and Graebner, 2007; Handfield and Melnyk, 1998; McCutcheon and Meredith, 1993; Meredith, 1998) and

\footnotetext{
${ }^{1}$ (Armenakis et al., 1999) used the construct of (personal) valence to explain that individuals will weigh the costs and benefits of adopting a change. Instead, we use the term direct benefit in this paper, because re-freezing requires the cost / benefit analysis to conclude in favor of benefit in the case of each involved individual.
} 
to exercise "controlled opportunism" (Eisenhardt, 1989) to explore emergent paths of inquiry.

Rather than focus on completed PIPs (and thus only retrospective data), we used a longitudinal approach that examined DevCo's experience as it occurred. We sought a rich understanding of experiences at the working level of PD engineers and managers (Adler and Clark, 1991; Bhakoo and Choi, 2013). Since our research time frame coincided with the PIP implementation, we had no preconceived notions about the outcomes. Moreover, studying the PIP implementation in "real time" limited bias from hindsight or recall (Staats et al., 2011; Van Oorschot et al., 2013). As an inductive study (Glaser and Strauss, 1967; Langley, 1999; Langley et al., 2013), our findings emerged through an iterative process wherein we repeatedly compared our data (from varied sources within DevCo, as described below) with concepts from different streams of literature about PIP implementation and organizational change (Van de Ven, 2007; Van Oorschot et al., 2013). Our basic steps were to (a) identify the initial frameworks that would guide our research, (b) observe the processes of stability and change as DevCo initially implemented the PIP, (c) sort the data into meaningful categories, (d) ground our observations with existing literature to develop propositions that established the theoretical relevance of our findings, (e) corroborate our propositions with further observations of DevCo's PIP implementation, and (f) re-ground our observations and refine the propositions. The following subsections further describe the research setting and our data collection and analysis activities.

\subsection{Research Setting}

DevCo is a division (800 employees) of a multinational corporation (MultiNat) with a large presence in several research, technology, and manufacturing industries. At the time of our research, MultiNat's annual report identified a workforce of over 200,000 employees, $\$ 50$ billion revenue, and $\$ 4$ billion profit. In the decade prior to our research, DevCo invested heavily to expand its product offerings for the power generation industry. Its product offerings focused on field prototype and limited fleet ( $<100$ units), which had the dual purpose of maturing DevCo's core technology and growing the renewable energy industry. DevCo's structure for its Engineering Department consisted of four groups. The Advanced Technology group was responsible for developing new technology within DevCo's portfolio. The Product Development group was responsible for developing product offerings using DevCo's technology. The Experimental Test group was responsible for verification and validation testing of configurations developed by both the Advanced Technology and Product Development groups. The Engineering Management Group (EMG) was responsible for defining processes and procedures to guide the work of the other three groups (including PIP implementation).

DevCo's investment spanned several cycles of personnel expansion and contraction that resulted from changes in its target markets. In 2004 (the year before we began our research) DevCo cancelled three highprofile development programs (because its technology was less mature than anticipated), lost contract bids 
with several potential customers (part of an industry trend where DevCo and its competitors all faced a weakened market), and reduced its workforce of 300 engineers by over $30 \%$. This downturn put DevCo's leadership team under considerable cost and schedule pressure, from both its customers and MultiNat, and accentuated the need to avoid mistakes in product launch decisions. In response, DevCo adjusted its portfolio to the new market conditions and emphasized controlling its PD activities. One mechanism for this control was implementation of MultiNat's PIP, a fusion of Lean and Six Sigma, to improve its PD processes (i.e., to improve competitiveness following the downturn, increase sales, and speed recovery by reducing the non-recurring cost of $\mathrm{PD}$ and the recurring costs of products that were complex to manufacture).

Table 1: Elements and heritage of MultiNat's PIP

\begin{tabular}{|c|c|}
\hline PIP Element & Source \\
\hline \multicolumn{2}{|l|}{ Process Improvement / Waste Elimination } \\
\hline $\begin{array}{l}\text { 5S (sort, straighten, sweep, standardize, and self-discipline) } \\
\text { Value stream management } \\
\text { Standardized operating procedures; standard work } \\
\text { Production process reengineering } \\
\text { Total preventive maintenance } \\
\text { Set-up reduction }\end{array}$ & Lean \\
\hline $\begin{array}{l}\text { Process management \& control } \\
\text { Process definition }\end{array}$ & Six Sigma \\
\hline \multicolumn{2}{|l|}{ Problem Solving \& Decision-Making } \\
\hline $\begin{array}{l}\text { Voice of the customer } \\
\text { Quality data and reporting }\end{array}$ & Six Sigma and TQM \\
\hline $\begin{array}{l}\text { Root cause analysis (five whys) } \\
\text { Mistake-proofing }\end{array}$ & Lean \\
\hline Stage-gate control for product introduction activities & $\begin{array}{l}\text { (Cooper et al., 2002; Cooper and Kleinschmidt, } \\
\text { 1993) }\end{array}$ \\
\hline \multicolumn{2}{|l|}{ Supporting Infrastructure (Operating System) } \\
\hline $\begin{array}{l}\text { Top management commitment } \\
\text { Training for quality } \\
\text { Employee involvement and teamwork (workforce management) } \\
\text { Role structure with improvement specialists and coaches }\end{array}$ & Six Sigma and TQM \\
\hline
\end{tabular}

The PIP originated as a set of grassroots, manufacturing quality improvement tools at another MultiNat division. At its core, the PIP intended to help groups measure their activities, identify problems, define ways to improve, and avoid repeating past mistakes. It aimed to accomplish this by using the elements in Table 1 to promote data-driven problem solving, decision making, and waste elimination. (Lean, Six Sigma, and Total Quality Management [TQM] elements are classified using the taxonomies proposed by Browning and Heath, 2009.; Schroeder et al., 2008; Zu et al., 2008).

Following its initial success, and assuming it was transferrable, Multinat expanded the PIP into a formalized structure containing common requirements for both manufacturing and office environments across all its divisions. MultiNat established a steering committee comprised of employees from each 
division, whose responsibility was to manage deployment of the PIP across the company. The committee defined four phases of PIP implementation: Qualifying (awareness of the PIP), Bronze (demonstrated competence with PIP tools and methods), Silver (demonstrated process control and improvement using the PIP tools and methods), and Gold ("world-class performance"). Each phase included required changes (e.g., improved processes or utilized tools) and criteria for progression to the next. By the Gold phase, the organization was expected to provide products and services of sufficiently high quality to motivate customers not to do business elsewhere.

Table 2: DevCo Product Lines and PIP Research Scope

\begin{tabular}{|c|c|c|c|c|c|c|c|}
\hline \multicolumn{3}{|c|}{ Product Line Activity } & \multicolumn{5}{|c|}{ Department at DevCo } \\
\hline & & & $\begin{array}{c}\text { Support } \\
\text { (HR / Legal) }\end{array}$ & $\begin{array}{c}\text { Business } \\
\text { Development }\end{array}$ & $\begin{array}{l}\text { Engineering } \\
\text { R\&D PD }\end{array}$ & $\begin{array}{c}\text { Operations / } \\
\text { Manufacturing }\end{array}$ & Supply Chain \\
\hline $\begin{array}{c}\text { Market } \\
\text { Segment \#1 }\end{array}$ & $\begin{array}{l}\text { Product } 1 \\
\text { Product } 2 \\
\text { Product } 3 \\
\text { Product } 4 \\
\text { Product } 5 \\
\text { Product } 6\end{array}$ & $\begin{array}{l}\text { Discontinued } \\
\text { Cancelled } \\
\text { Continued } \\
\text { Continued } \\
\text { Launched } \\
\text { Launched }\end{array}$ & & & $\begin{array}{c}\text { Research focus } \\
\text { for Silver }\end{array}$ & $\begin{array}{c}\text { Additional } \\
\text { Research focus }\end{array}$ & \\
\hline $\begin{array}{c}\text { Market } \\
\text { Segment \#2 }\end{array}$ & $\begin{array}{l}\text { Product } 7 \\
\text { Product } 8 \\
\text { Product } 9 \\
\text { Product } 10 \\
\text { Product } 11\end{array}$ & $\begin{array}{l}\text { Cancelled } \\
\text { Cancelled } \\
\text { Cancelled \& } \\
\text { Relaunched } \\
\text { Continued } \\
\text { Launched }\end{array}$ & & & $\begin{array}{c}\text { Planning \& } \\
\text { Implementation } \\
\text { Stages }\end{array}$ & $\begin{array}{c}\text { for Gold } \\
\text { Planning Stage }\end{array}$ & \\
\hline
\end{tabular}

In 2004 MultiNat initiated a large-scale certification effort at all of its divisions. This effort increased the uniformity of PIP implementation and assessment by imposing a single set of requirements and certification criteria, defined centrally by MultiNat. Due to the scope of the PIP revision, DevCo and other divisions that previously achieved Bronze had to be recertified. (DevCo completed its Bronze recertification in 2004.) DevCo treated the Silver Certification as a case of implementing the PIP for the first time. (MultiNat's PIP steering committee shared this view.) The PIP deployment across DevCo's entire business unit encompassed its Business Development, Support (e.g., Legal and Human Resources), Engineering, Operations, and Supply Chain departments. Our unit of analysis was the PIP implementation in DevCo's Engineering Department as it supported the development efforts for two separate markets (six products in one market, five in another) — see Table 2. DevCo's cross-functional teams on each product line included personnel from the rest of the business unit. Our research focused on the effect of the PIP implementation on enabling the engineering staff on those teams to more effectively do their work.

DevCo served as a representative case for the phenomena of theoretical interest identified by the two challenges in Section 2: articulating PIP principles in PD (the contextual challenge) and planning and managing the behavior changes for successful PIP implementation (the organizational challenge). Although 
the company had previously implemented several tools to make its PD activities more effective ${ }^{2}$, the PIP was the only active initiative being used to improve operational efficiency and effectiveness at the time of our research. As DevCo did not significantly change its technology or product offerings during the period of our research, these variables were also essentially held constant. The emphasis on the PIP allowed our study to focus on the variables of interest relative to the contextual and organizational challenges of implementation.

\subsection{Data Collection}

Our 24-month study at DevCo involved the three phases shown in Table 3: Silver Planning, Silver Implementation, and Gold Planning. The first author was a full-time ( $>40$ hours per week) employee in the six-person Engineering Management Group (EMG). Along with another EMG member, he shared responsibility for defining and executing the PIP implementation strategy within DevCo's Engineering department. This immersive participation at DevCo enabled us to "uncover real "unwritten-rules-of-the game' in a manner that [enabled] diagnosis and sometimes change and improvement" (Suckley and Price, 2013:174). It provided us with data about motivations for what the leadership at MultiNat and DevCo wanted the PIP to accomplish, as well as consequences of the PIP implementation based on responses from mid-level managers and working-level engineers. (Schein (1987) referred to these as back-stage and frontstage dynamics of organizations, respectively.) The first author's role enabled us to collect data oriented towards a clinical view of the PIP implementation - what DevCo learned during the Silver Certification efforts, intended and unintended consequences of that effort, and how it could more effectively encourage adoption of PIP tools and methods during the Gold Certification. The revealed data provided improved understanding of DevCo's dynamics_-providing building blocks for both improved theory (Schein, 1987:55) and increased practical relevance (Holmstrom et al., 2009).

Our primary sources of data were company communications, meetings, and semi-structured interviews, as summarized in Table 4. Each meeting included two to fifteen participants. We used semi-structured interviews during both individual discussions and meetings. Overall, we interviewed over 80 people. We recorded data through a combination of ethnographic field notes (Emerson et al., 1995) and meeting minutes. DevCo's security policy prohibited video or voice recording devices. Physically participating in meetings and discussions enabled us to capture non-verbal cues such as posture and tone of voice, which

\footnotetext{
2 These tools included concurrent engineering (CE), quality function deployment (QFD), integrated product development (IPD), and design for manufacturing and assembly (DFMA) ((e.g., Boothroyd et al., 1994; Chen et al., 2010; Clausing, 1994; Hjort et al., 1991; Roemer and Ahmadi, 2010; Sobek II et al., 1999)). It is outside the scope of this paper to discuss whether these tools achieved sustainable results at DevCo. As a mandatory change, the PIP emphasized implementing the tools in Table 1 in a manner that was largely agnostic to these previous efforts.
} 
aided in understanding and interpreting our collected data. We were able to observe "anomalies, blank looks, ... and various other kinds of emotional responses" (Schein, 1987:39) to better understand reactions to the PIP.

Table 3: PIP Phases and Associated Research Emphasis

\begin{tabular}{|c|c|}
\hline PIP Phase & Clinical Research Focus \\
\hline $\begin{array}{l}\text { aning } \\
2005)\end{array}$ & $\begin{array}{l}\text { - Preparations taking place prior to launching the Silver Implementation phase for the Engineering } \\
\text { department } \\
\text { - Understanding required manpower and determining how to adapt the PIP resources and assessment } \\
\text { material for use at DevCo }\end{array}$ \\
\hline $\begin{array}{l}\text { Silver } \\
\text { Implementation } \\
\text { (Jun 2005 - Jun } \\
\text { 2006) }\end{array}$ & $\begin{array}{l}\text { - Conducting tactical planning to discuss the health of the certification effort and any changes in } \\
\text { approach, and working with PIP staff to conduct the actual certification assessments } \\
\text { - Discussing execution of the Silver certification, understanding questions about implementing the PIP at } \\
\text { DevCo, preparing material for the Silver assessment, and obtaining feedback on the perceived benefits } \\
\text { (or lack thereof) from the PIP } \\
\text { - Observing the PIP material presented in training sessions and division all-hands meetings } \\
\text { - Explaining the PIP elements and the intent of the Engineering Management Group (EMG) for adapting } \\
\text { them at DevCo, and discussing areas of confusion, clarity, and perceived relevance } \\
\text { - Coordinating where multiple improvement teams (either within Engineering or between Engineering } \\
\text { and Operations) sought credit for improvement during the Silver assessment } \\
\text { - Ensuring that, as downstream "customers" whose feedback was required during the assessment, any } \\
\text { day-to-day operational issues where Engineering contributed to waste in Operations departments were } \\
\text { addressed }\end{array}$ \\
\hline $\begin{array}{l}\text { Gold Planning } \\
\text { (Jul 2006 - Dec } \\
\text { 2006) }\end{array}$ & $\begin{array}{l}\text { - Defining strategy to incorporate lessons learned from the Silver Implementation phase into the planning } \\
\text { for the Gold certification efforts } \\
\text { - Addressing criteria that the engineering teams and to improving alignment and collaboration in process } \\
\text { improvement activities between the Engineering and Operations departments. } \\
\text { - Defining strategy for developing joint Engineering/Operations improvement activities in support of the } \\
\text { Gold certification }\end{array}$ \\
\hline
\end{tabular}

Table 4: Data Sources

\begin{tabular}{ll}
\hline Data Source & Summary \\
\hline Meetings & - Weekly Engineering Management Group (EMG) meeting, which included the PIP as an agenda item \\
& - Recurring (weekly or bi-weekly) meetings regarding the Silver Certification held by functional \\
& managers in the Engineering department \\
& - Recurring (weekly) meetings with teams responsible for collecting data for the Silver Certification \\
\hline Communications & - Mandatory 1-2 hour training sessions on the PIP that DevCo held for the Engineering department \\
& - PIP presentation materials from DevCo's all-hands meetings (attended by all employees) \\
\hline Semi-structured & - Interviews with working-level engineers assigned to the different Engineering teams that prepared \\
Interviews & materials for the Silver Certification \\
& - Interviews with managers in the Operations department, who were also going through the PIP \\
& implementation and assessment \\
& Online interviews about the PIP with participants in MultiNat's employee scholar program who held \\
& similar responsibilities at other MultiNat divisions within their Engineering, Finance, and Operations \\
& departments
\end{tabular}

During each PIP implementation phase, we organized our questions to probe whether our informants identified themes related to our initial framework in section 2.3 (see the sample set in Table 5). During these interviews, we approached DevCo's employees as both objects of study and expert witnesses (Levy 
and Hollan, 1998). As objects of study, our questions probed their personal experiences with the Silver certification. As expert witnesses, our questions probed their knowledge of DevCo's culture and behavior as it pertained to the PIP. Both sets of responses provided data to evaluate the Silver certification efforts against our initial framework in Section 2, with a view toward improving DevCo's PIP implementation efforts during the Gold certification phase.

\section{Table 5: Sample Interview Questions}

- Which specific elements of the PIP do you find confusing?

- In your daily activities, are there activities or dynamics that you view as taking up lots of time without providing much value (churn)?

- Is the PIP data collection capturing any of these activities?

- What activities are you being asked to complete for the PIP?

- Do you think that any of the activities the PIP requires are "not real engineering work"?

- What do you think quality means in a PD context like this?

- Do you think that process improvement and innovation are mutually exclusive?

- What do you think should be done to reduce the types of problems that are attributed to causing the recent program cancellations?

- Do you think interventions like the PIP are improving quality or addressing these problems?

- What do you think should be done to make the PIP more effective at DevCo?

Because we wanted to gain a deeper understanding of the PIP at DevCo from a specific informant population (working-level engineers and mid-level managers), we treated our data as a non-probabilistic "judgment sample" (Bernard, 2002). We looked for data saturation, the points where converging lines of inquiry (Guest et al., 2006; Levy and Hollan, 1998; Yin, 2003) identified empirical themes, which we compared with our initial framework. We also seized opportunities to pursue new directions based on our informants' feedback. For example, when we asked one manager about quality and innovation being contradictory, he replied:

I don't think they are contradictory. I think they are orthogonal. For my team to innovate more effectively, they need to share information with each other. Using the PIP to improve quality control doesn't address that need. I'm not interested in writing down processes to micromanage how they share information by forcing them to talk to specific experts. I accept some inefficiency in information sharing as part of working with new technology.

This statement contained several themes from the input conditions in section 2.3, including the manager's view of valued work (the team should innovate more effectively), lack of a discrepancy (he viewed the PIP's documentation requirements as micromanaging how information was shared, which he did not consider useful), and limited appropriateness or direct benefit (the manager was skeptical that the PIP would improve his team's performance).

\subsection{Data Analysis}

Similar to other longitudinal studies of organizational change (Lok and De Rond, 2013; Rerup and 
Feldman, 2011; Van Oorschot et al., 2013), we grounded the descriptive observations from our data with theoretical elements from section 2.3 that provided a selective focus for observing change. Consistent with Yin (2003), Stuart et al. (2002), and Ketokivi and Choi (2014), we elaborate theory about transferring PIPs to PD contexts by comparing empirical evidence from each PIP phase with existing theories of organizational change. This synthesis is advocated by grounded theory research (Eisenhardt and Graebner, 2007), for which single case studies can be useful (Barratt et al., 2011; Browning and Heath, 2009; Flynn et al., 1990; March et al., 1991).

Human creativity and intuition, not just data, are essential for developing theory (Mintzberg, 1979), so we needed a "creative leap" (Langley, 1999: 691) while at the same time remaining grounded in the data. Our approach was therefore three-fold. First, we used our field notes, interview transcripts, and relevant documents to build a database of observations that helped us understand the PIP implementation at DevCo. Because of our interest in PIP transferability between OM contexts, we sought to understand how well the PIP's principles were understood at DevCo (with respect to both intended and unintended consequences of the PIP implementation). We organized the data into categories that represented the articulation of principles like value and waste in the PIP design and how DevCo's engineers experienced them. Through this approach, we were able to use our data to identify a breadth of themes rather than merely count which ones were at the forefront of our informants' minds.

Second, we evaluated data within and between each PIP phase (Silver planning, Silver implementation, and Gold planning) to identify emerging themes, compare them with our initial framework (Ayres et al., 2003; Rerup and Feldman, 2011), and ensure that our findings were not derived from a single phase. We examined the data for commonalities and variation across the experience of our informants (q.v., the data saturation and new ideas noted in Section 3.2). Our analysis within the Silver planning and implementation phases yielded distinct themes pertaining to motives for the implementation (what MultiNat and DevCo's leadership wanted the PIP to accomplish), consequences of the implementation (how DevCo's engineers experienced the PIP), and different interpretations about the expected versus achieved outcomes from the Silver Implementation. Our analysis between the Silver implementation and Gold planning phases yielded themes about the PIP as an initiative that could add value for DevCo as a PD company. We grounded our analysis of these observations in existing literature about PIP design, PIP transference between OM contexts, and organizational change. This led us to organize our emerging themes to examine whether the change at DevCo from the PIP Silver certification was indeed substantive (i.e., the PIP was widely "used and understood" (Zbaracki, 1998: 632)) or merely symbolic (i.e., DevCo just created the requisite artifacts to gain the PIP certifications by the declared milestones). We used these insights to develop theoretical propositions that summarized the themes from our findings. 
Third, we analyzed the data from two complementary perspectives. The first author used his ethnographically "thick" understanding of DevCo's practices to ground the descriptive, clinical observations with core themes in the existing literature. The second author critically reviewed the observations against alternative explanations to improve the quality of our theoretical findings (Rerup and Feldman, 2011). By exploring our data from both perspectives, we (1) identified key issues, variables, relationships, and patterns in the data, with a specific view towards examining patterns that enhanced or ran counter to established theory, (2) proposed key factors and relationships to identify gaps between the data and existing theory, and to explain how and why they matter (Handfield and Melnyk, 1998), (3) eliminated initial propositions that lacked sufficient evidence or theoretical connection, and (4) strengthened the remaining propositions to ensure they integrated into an overall framework instead of expressing individual themes (Ayres et al., 2003). In the end, we achieved a substantial but imperfect match between our propositions and our case study data. This was expected, since a set of independent variables does not explain $100 \%$ of the variation in a set of dependent variables (Mintzberg, 1979), even in quantitative research. Like Sutton and Callahan (1987), we accepted a good rather than a perfect fit between theory and data.

To control for construct validity and reduce the risk of sensemaking bias, we conducted additional interviews to cross-check emerging themes and propositions with input from diverse functional areas, outside our target population. (Beyond working-level engineers and mid-level managers from the four Engineering groups at DevCo, our informants included senior and mid-level managers in Operations, midlevel managers from MultiNat's PIP steering committee, and working-level employees responsible for implementing the PIP at other MultiNat divisions.) We triangulated findings from our interviews through a review of PIP policy documents from MultiNat's central office and participation in monthly steering committee meetings for individuals responsible for PIP strategy and deployment in each MultiNat division. This provided "substantive coverage" (Kunda et al., 2002) for our findings, which increased confidence in their internal validity.

To further ensure correct documentation and interpretation of events, the first author wrote an internal report at the end of the Silver Implementation phase that summarized the PIP status for DevCo's Engineering department (including lessons learned from the Silver Implementation phase and recommendations for the Gold Planning phase). He revised the initial report based on reviews by the four individuals responsible for the PIP's implementation in DevCo's Engineering department. He also interviewed six Engineering managers to discuss the completion of the Silver assessment, understand ways to improve the facilitation provided by the EMG, and identify improvements that the Silver Implementation did not address. These ten validation interviews were with individuals who were also informants during the earlier data gathering. The diminishing number of feedback items through these review cycles provided a reasonable basis for accepting our refined data and analysis as reliable and valid. 


\section{Findings from DevCo's PIP Implementation}

\subsection{Assessing Symbolic Success: The Audit and Its Results}

In 2003, DevCo's president declared two milestones for the PIP implementation: Bronze recertification by December 2004 and Silver by June 2006. Achieving Bronze certification required only demonstrating awareness of key principles from the PIP (e.g., customer satisfaction, process control), while achieving Silver certification required demonstrating that these principles were being adopted. The day-to-day execution of DevCo's PD routines was expected to change in line with this adoption. The mechanism to assess this adoption was the Silver Audit, which took place between April and June of 2006. Managers and teams from the Engineering department presented evidence of how they met the Silver requirements during weekly meetings with two auditors (both employed by DevCo). They organized the evidence in a spreadsheet report that listed each PIP item, its requirements, expectations of what should be presented to satisfy the requirements, and specific links supporting compliance data. The full audit table decomposed each of the categories from Table 1 into over one hundred items. Table 6 summarizes some examples.

\subsection{Assessing Substantive Success: PIP Implementation "As Expected" versus "As Experienced"}

The Engineering department produced adequate evidence to convince the auditors that it had satisfied MultiNat's criteria for the Silver certification before the declared June 2006 deadline. Thus, by its own criteria, DevCo achieved symbolic success. However, as stated in Section 1, an organization may achieve symbolic success without substantive change actually occurring. MultiNat's PIP architects anticipated this possibility, as their review of the PIP implementation at several MultiNat locations in 2004 had shown consistency at the Bronze and Gold levels but considerable variation at the Silver level (variation in the sense that some sites had achieved Silver without demonstrating all of the architects' anticipated outcomes). This variation helped motivate them to revise the PIP rules and launch the recertification effort mentioned in Section 3.1. Hence, we wondered whether DevCo's symbolic success with the Silver certification also included substantive changes to its PD practices. To explore this question, we organized our findings in further detail according to the framework in Section 2.3, which claims that an effectively implemented PIP will progress through Lewin's three stages of unfreezing, changing, and re-freezing. We specifically examined the relationships between how MultiNat and DevCo crafted the change message and how DevCo's engineers experienced the PIP.

Table 6: Summary of Silver Audit Data

\begin{tabular}{llll}
\multicolumn{1}{c}{ PIP Item } & $\begin{array}{c}\text { PIP } \\
\text { Requirement } \\
\text { (from MultiNat) }\end{array}$ & $\begin{array}{c}\text { PIP Compliance Criterion } \\
\text { (from DevCo's PIP } \\
\text { Auditors) }\end{array}$ & $\begin{array}{c}\text { DevCo's Compliance Activity } \\
\text { (presented during the audit) }\end{array}$ \\
\hline Process Improvement & Waste Elimination & & \\
\hline $\begin{array}{l}\text { Value stream } \\
\text { management \& } \\
\text { process re- }\end{array}$ & $\begin{array}{l}\text { Value stream map } \\
\text { (VSM) exists for } \\
\text { area being audited }\end{array}$ & $\begin{array}{l}\text { VSM used to identify key } \\
\text { deliverables, downstream } \\
\text { customers, and points in the }\end{array}$ & Showed VSM was not the proper tool for PD \\
\end{tabular}




\begin{tabular}{|c|c|c|c|}
\hline engineering & & $\begin{array}{l}\text { value stream requiring process } \\
\text { control / definition } \\
\text { Kaizen events implemented to } \\
\text { improve processes based on } \\
\text { VSM results }\end{array}$ & structure matrix (DSM) instead \\
\hline $\begin{array}{l}\text { Process definition \& } \\
\text { standard work }\end{array}$ & $\begin{array}{l}\text { Key processes } \\
\text { identified and } \\
\text { defined }\end{array}$ & $\begin{array}{l}\text { Demonstrate rationale for } \\
\text { selecting key processes \& show } \\
\text { they are under control (above) } \\
\text { and defined (standard work) }\end{array}$ & $\begin{array}{l}\text { Displayed engineering processes using the } \\
\text { organization of the PIP tool } \\
\text { Showed list of processes with governing work } \\
\text { documents for each engineering function } \\
\text { (e.g., software, systems engineering, } \\
\text { mechanical and electrical design) }\end{array}$ \\
\hline $\begin{array}{l}\text { Total preventive } \\
\text { maintenance }\end{array}$ & TPM in place & $\begin{array}{l}\text { No requirement for Silver, but } \\
\text { criteria existed for Gold }\end{array}$ & $\begin{array}{l}\text { Presented plan to ensure that IT infrastructure } \\
\text { was in place, software licenses, lab } \\
\text { equipment, etc. }\end{array}$ \\
\hline \multicolumn{4}{|c|}{ Problem Solving \& Decision-Making } \\
\hline $\begin{array}{l}\text { Voice of the } \\
\text { customer }\end{array}$ & $\begin{array}{l}\text { Customer } \\
\text { satisfaction survey }\end{array}$ & $\begin{array}{l}\text { Average score at least } 4 \text { out of } \\
5 \text { with action plans in place to } \\
\text { improve low scores }\end{array}$ & $\begin{array}{l}\text { Provided list of internal customers queried for } \\
\text { the survey, with results showing average } \\
\text { score was at least } 4 \text { out of } 5 \text {. }\end{array}$ \\
\hline Mistake-proofing & $\begin{array}{l}\text { Mistake-proofing } \\
\text { used to improve } \\
\text { processes }\end{array}$ & $\begin{array}{l}\text { Example of mistake-proofing } \\
\text { being applied }\end{array}$ & $\begin{array}{l}\text { Presented an example from development } \\
\text { program of errors identified and steps taken } \\
\text { to correct them. The auditor accepted the } \\
\text { evidence and said that the corrections would } \\
\text { need to be applied to DevCo's other programs } \\
\text { for the Gold audit. }\end{array}$ \\
\hline \multicolumn{4}{|c|}{ Supporting Infrastructure (Operating System) } \\
\hline $\begin{array}{l}\text { Top management } \\
\text { commitment }\end{array}$ & $\begin{array}{l}\text { Leadership supports } \\
\text { PIP }\end{array}$ & & $\begin{array}{l}\text { Showed that Engineering teams were formed } \\
\text { to collect data for each section of the audit } \\
\text { spreadsheet, and that a manager was assigned } \\
\text { to lead each PIP team }\end{array}$ \\
\hline $\begin{array}{l}\text { Employee } \\
\text { involvement and } \\
\text { teamwork (workforce } \\
\text { management) }\end{array}$ & $\begin{array}{l}\text { Cultural alignment } \\
\text { (workforce supports } \\
\text { PIP) }\end{array}$ & & $\begin{array}{l}\text { Showed that } 100 \% \text { of engineers assigned to } \\
\text { participate on a PIP team }\end{array}$ \\
\hline
\end{tabular}

\subsubsection{Months 1-6: Unfreezing with the PIP}

DevCo's PIP implementation coincided with the market downturn and commercial pressure discussed

in Section 3.2. As researchers, we interpreted these environmental factors as potential unfreezing forces to motivate a change in DevCo's status quo. Our informants indicated that they viewed the environmental factors differently.

I have been through several downturns like this during my career at DevCo. I learned to make sure my resume was always up to date, because I didn't know if the company would fold or not. What we are going through right now is not much different. [Experienced engineer]

This whole idea of external feedback that the PIP emphasizes is tricky at DevCo. In emerging markets, you often need to convince customers to buy your product. It's tough to convince someone who operates with that mindset to use feedback as an infallible guide to what you should do differently. The PIP guidance for external feedback can come across like that. [EMG group member]

MultiNat's mandate for PIP implementation was a second environmental factor that could have been an unfreezing force. DevCo's management did not seek to establish a shared understanding with its employees about how the company would achieve the mandate. Rather, they presented it as an act of 
compliance commitment (Armenakis et al., 1999): DevCo's management was complying with MultiNat and thus expected its employees to comply with their directive. Consider the following statements from DevCo's president (both made during all-hands meetings):

Kevin, stand up. Kevin is the Lone Ranger. He is responsible to make sure we achieve the Silver Certification.

If we do not achieve the Silver certification by the June milestone, there will be no Christmas. Please consider delaying your vacation plans until the audit is complete.

We committed to MultiNat that we would achieve these levels. It is important that we keep those commitments.

A third potential unfreezing force came from the activities prescribed by the PIP. A general tenet of PIPs is that organizations attain a more accurate view of their current state operations by adopting structured techniques for data collection and problem solving (Table 1). The visualization of waste and inefficiencies should then create a pull for improvement (Zmud, 1984) that is addressed by the PIP tools being pushed into practice. DevCo's PIP required groups to survey internal stakeholders who were part of their value stream, upstream and downstream, to understand the perceived quality of their services and identify areas of waste. For DevCo's Engineering department, this involved collecting survey data from the other departments in Table 3.

The survey used the input-process-output (I-P-O) model (Ilgen et al., 2005) under the premise that the Engineering group received inputs, executed a process (or set of processes), and produced outputs, about which their downstream customers could assess value via a satisfaction survey. However, the survey results did not clearly identify waste and inefficiencies in DevCo's engineering processes in ways that motivated the engineers to change. For example:

Why are we measuring internal defects when the majority of difficulties we experience in executing our work are caused by other groups? [Engineering manager A]

The PIP requires us to document lessons learned, but most of our lessons learned are things the group giving us information needs to do differently. [Project engineer]

The reason our survey feedback is this way is that they don't understand the complexity of our process. [Engineering manager B]

[Group A] got the Silver certification last week, because they evaluated themselves. People who interact with them would not agree that their output is anywhere near that good. [Engineering manager $\mathrm{C}]$

DevCo's engineers did not agree with the interpretations of their upstream and downstream customers. They discounted the feedback from other departments, pretended some problems identified in the survey results did not exist, and were skeptical about the relevance of a change message driven by external feedback:

One characteristic of emerging markets is the need to assume that most customers for your product 
don't exist. The ones who do must be reeducated so they can fully appreciate what you're offering them. The last thing you want to do is assume they are right about whether what you offer them provides value. [DevCo engineer]

\subsubsection{Months 6-18, Changing: Adopting the PIP}

MultiNat's PIP architects wanted the PIP's principles ingrained in all aspects of daily activity throughout its divisions. They used the operating system (OS) metaphor to symbolize a desire that problemsolving tools and methods for reducing variation be embedded in written processes, procedures, and standard work - not just in the heads of individual engineers. They presumed that such embeddedness would then require only limited, explicit reinforcement of the PIP. Both of these characteristics made the OS an appealing symbol for MultiNat's PIP architects. The term was used routinely in communications about the PIP, as well as in discussions among the PIP steering committee (who regularly referred to the PIP as "the operating system" during their meetings).

We found that DevCo's engineers did not share this view. For them, the OS symbolized an intent to transform work they believed required high levels of conceptual and cognitive skill (what Blackler (1995) called embrained knowledge) into work that was embedded into automated routines. They often stated that PD activities required significant human skill. During a meeting in preparation for the Silver audit, one engineer stated emphatically, "You can train a monkey to follow a process. You cannot train a monkey to do the work we do." As a result of this skepticism, DevCo's engineers did not believe that the PIP's tools could facilitate structured problem solving in their environment. They also did not view repeatability in their daily activities as a desirable characteristic. Consider the following discussion:

The PIP is a waste of time. [Engineer 1]

You say that, but you're the first person I see writing a macro with your spreadsheets to make sure that your analysis is repeatable. You do this because it makes your work more consistent and makes your life easier. Those are the types of opportunities the PIP is looking for. [EMG member]

People need to think critically about the work they do. As soon as you codify a tool like this, they will use it without thinking about the inputs or the outputs in their analysis. Let [Engineer 1] write his own macro, but don't try and standardize it so that the rest of the department is forced to use it. [Engineer 2]

Despite skepticism about the prescribed tools and behaviors, we also found that DevCo's engineers were interested in working more efficiently. Indeed, DevCo's engineers frequently discussed the waste embedded in their daily activities. This frustration signified both dissatisfaction with DevCo's status quo and willingness to use PIP principles to improve their work:

None of us disagree with the philosophy you're proposing [regarding the problems that the PIP should address]. Many of us don't see how the extensive and overlapping audit requirements support that philosophy. [Engineering manager]

I could get excited about the PIP's statistical process control activity and data management tool if you show me that it is a reliable, fast way to collect field problems. [Project engineer] 
This combination of dissatisfaction with the status quo and willingness to use PIP principles and tools showed us that the concerns of DevCo's engineers - how to manage information flow and scarce resources to conduct PD efforts in ways that select design solutions efficiently and effectively-overlapped with the concerns of the PIP's architects. These overlapping concerns suggested that the PIP could apply continuous improvement principles to PD work in the same way that traditional improvements applied those principles to production tasks. This potential is reflected in the following discussion:

People assume that the goal of the PIP is to lock down processes. That leads to concerns that it stifles innovation. What if you defined critical processes as ones that need to change? For example, an auditor could say "I will be back in six months. I expect to find changes to each of the key processes we discussed today based on the weaknesses you have identified." [EMG member]

You are right that the PIP criteria do not prohibit this approach. It would take some work to explain it and manage the expectations of the auditor. [Kevin]

Our data suggested that the PIP could help DevCo's engineers identify opportunities to improve their PD activities (the knowledge-work equivalent to control charts being out of bounds) instead of seeking to transform knowledge work into production tasks. The following statements provide more concrete examples.

It is frustrating that people discard the idea of process improvement when they say it doesn't apply to our labs. I would love to standardize how we collect information that defines a test, and also how we store it afterwards. I don't want to restrict the actual tests - that is the real creative work to explore new technology. I just don't feel like there's anything creative about all the time we waste setting up tests and looking for data afterwards. [Engineering manager]

Yesterday's presentation from MultiNat reinforced that the PIP is not relevant here. I understand its value for manufacturing. We don't have anything stable enough that we want to lock it down and not try something different. I do believe [DevCo] must find a cheaper, faster way to develop new technology ideas. If we went to a company with the platform we sold in 2004, no one would want it because it is obsolete. Maybe there are tools in the PIP that we could use to facilitate that change. [Engineering manager]

Particularly in the transition to the Gold Planning phase, our informants began to describe a different way that DevCo could operate (responding in part to the market pressures described in Section 3.1). Their descriptions provided insights about how the PIP could facilitate that different operation. These insights encompassed control of both tools (e.g., the checklists, forms, and procedures that are typical targets for PIP efforts) and behaviors, or patterns of action (Pentland and Feldman, 2008), that could improve the learning behaviors (Choo et al., 2007) of the teams doing PD work. The discussion below illustrates these findings.

In Systems Engineering we use the principle of a performance-based specification quite a bit. Could we use that idea with the PIP? For example, DevCo's top management could define the high-level functional requirements for the PIP based on explicitly linking it to current business needs. The Engineering managers could identify the solutions to the requirements and decompose these requirements into specifications for activity within their respective groups. They could then reintegrate the individual activities into a complete output that meets the original performance requirement. [EMG member] 
That approach is not expressly prohibited by MultiNat's PIP architects. It's certainly uncommon. Using your SE example, the more common practice is to specify solutions rather than functional requirements. [Kevin]

\subsubsection{Months 18-24, Re-freezing with the PIP}

According to Armenakis and Harris (2002), the adoption stage is an experimental period during which employees may still choose to reject a proposed change. Institutionalizing the change into a new set of norms (re-freezing) requires providing resources to reinforce the changes made and demonstrating direct benefit (answering the "What's in it for me?" question). Section 4.2.2 showed that, despite the incomplete unfreezing discussed in Section 4.2.1, DevCo's employees acknowledged that "there might be something in it for me." Thus, the experimental period of change adoption, which ended with symbolic success of achieving the Silver certification milestone, included interest in substantive implementation during the Gold phase. However, we found several potential barriers to this interest.

Besides strongly embedding the PIP across MultiNat's divisions, the PIP's architects intended for it to be imposed organically rather than externally. During one steering committee meeting, the idea of process control requiring specialists who were competent in specific software tools (such as Minitab) was actively discussed and ultimately rejected, because requiring specialists detracted from the PIP being a grassroots improvement program. At DevCo, we found that this vision of organic change was problematic because of ambiguity regarding which resources were required to institutionalize the PIP and where those resources should be applied. One of the MultiNat managers we interviewed questioned whether grassroots change was an adequate mechanism to embed the PIP principles.

DevCo's Vice President of Engineering stated that the company's investment of more than one million dollars in the PIP during the Bronze and Silver phases signified its commitment to implementation. However, these funds were used primarily for one-hour awareness classes, providing just an overview of the PIP tools, with limited discussion of how to apply them.

DevCo's communications about the PIP did not make a strong case for its relevance to daily activities in ways that demonstrated its short-term value. In 2005-2006, during each quarterly, 60-90 minute, allhands meeting, the PIP received a single slide. Each meeting emphasized that DevCo already considered itself the dominant player in its market - a dissonant message from the one that best-in-class performance would only be achieved by PIP progression to Gold. By not using these meetings as a communication channel to address questions about appropriateness, ambiguity of resources, and direct benefits, DevCo missed opportunities to address the barriers to institutionalizing the PIP. By not communicating small wins, such as informing the organization when individual groups passed their Silver assessments, DevCo tacitly conveyed that, while non-compliance to PIP milestones would be punished, compliance would not be celebrated. The result was a diminished sense of personal benefit and a lack of motivation to support the PIP implementation from DevCo's engineers. For examples: 
The PIP came from a high-volume manufacturing environment, which we don't have. It is used at divisions that are established players in mature markets, which we are not. It is marginally relevant at best. It is probably flat-out wrong because the other divisions do not understand how we operate here. [Engineering manager]

The most difficult thing I've found about getting others to accept the time demands of the Silver certification is that I can't clearly answer the questions, "Why should I do this? How will I concretely benefit from it?" Appealing to happy customers does not work if you consider customers ignorant and unable to evaluate important product features. Appealing to the goal of becoming the best in the world does not work if you believe you already are. Appealing to future improvements does not answer the question, "If my resources are already scarce, why should I invest in an activity that benefits someone else, but not me?" [EMG Member]

Why are we doing this when management has not given us the resources to fix problems in the past? They will use this data to create charts that allow them to yell at us about how we should be doing things differently with no support. [Project engineer]

MultiNat's PIP architects intended for higher levels of PIP progression (from Bronze to Gold) to correspond with improved quality and increased market share. The waste in day-to-day activities was supposed to steadily decrease, culminating in being "world class" upon reaching the Gold level. DevCo's president reinforced this view with his statements that the firm would benefit from the PIP in the future-e.g.:

When we get to mass production and our products are rolling off the assembly line, we will need the PIP to help us operate.

Hackman and Wageman (1995) found that during times of organizational change, challenging targets that focus on reducing mistakes will not increase employee motivation to identify and implement improvements. In DevCo's case, many of our informants believed that the Silver certification was achieved without any substantive change. Thus, achieving the Silver certification milestone actually created disillusion about adopting the PIP:

I didn't realize how broken our process was until we started working on this certification activity. I feel hypocritical pulling data together for the Silver assessments, even though it's been made very clear that not passing in June is unacceptable. [PIP implementation lead]

At a celebration lunch for the Engineering department upon reaching Silver, the Engineering VP's speech framed the accomplishment merely as a precursor to the hard work ahead to reach Gold. A manager at the first author's table said with a weary sigh, "process improvement."

\section{Discussion: Implications for the Effectiveness of PIP Implementation}

Figure 1 summarizes our findings against the framework for managing a change initiative in Section 2.3. The themes from Section 4 show that DevCo's implementation of the PIP is more than simply a case of things "going wrong." Our informants expressed both dissatisfaction with the Silver Implementation phase and interest in performing their PD work more effectively. DevCo's management was specifically looking for lessons learned and improvements as it entered the Gold Planning phase. These themes reflect the barriers and opportunities encountered when implementing a PIP in a complex, sociotechnical system. 
These conditions are common in large organizations where many OM practitioners and researchers do their work. In the rest of this section, we discuss these findings in more detail, distill eight propositions, and identify opportunities for future research.

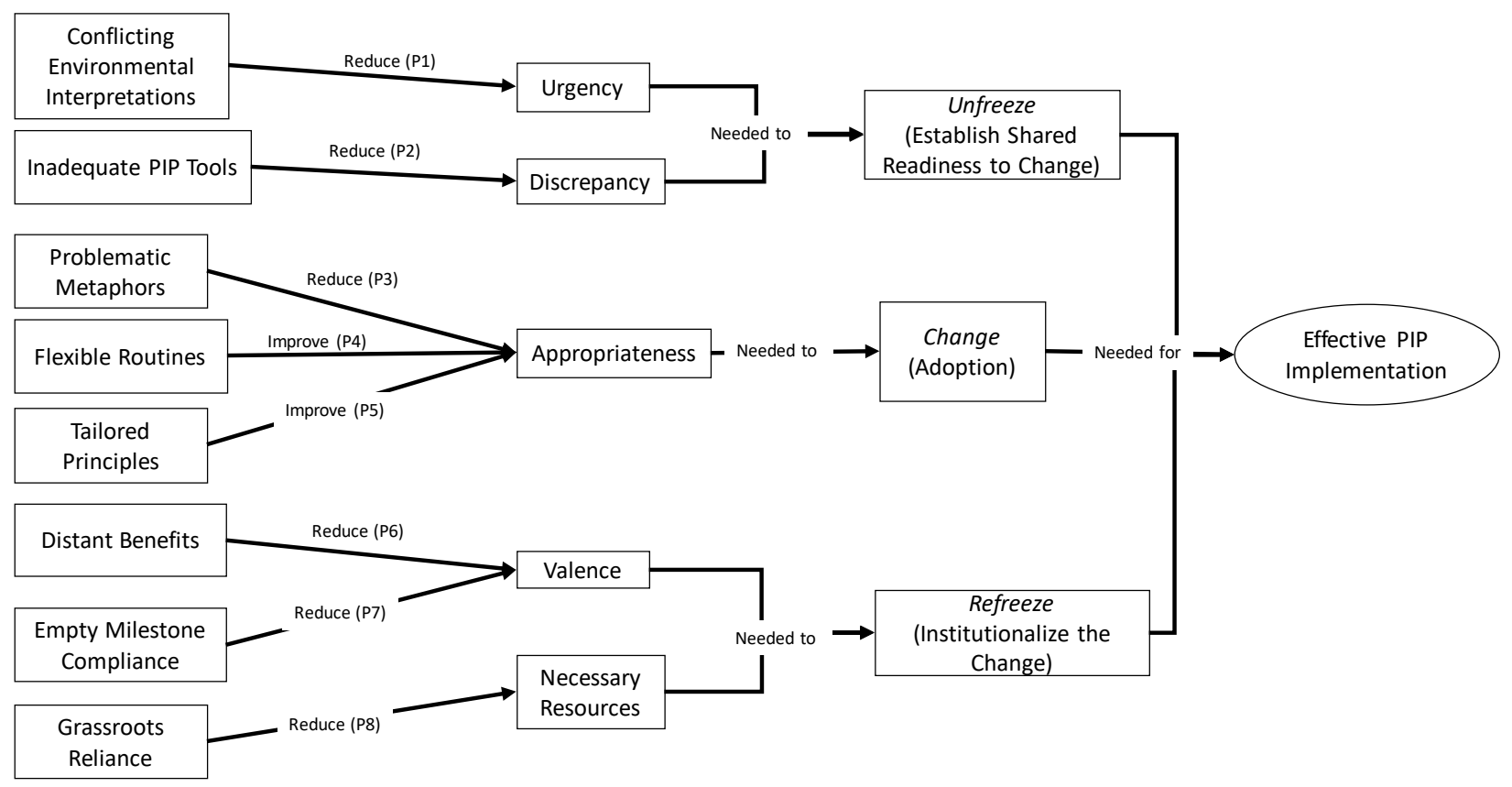

Figure 1: Factors proposed to affect the effectiveness of PIP implementation in PD contexts

\subsection{Unfreezing: Implications Regarding Readiness to Change}

\subsubsection{Conflicting Environmental Interpretations}

Discussions of change implementation often emphasize the importance of conveying urgency from the change agent's perspective and understanding how this urgency is perceived by the change recipients (Jiao and Zhao, 2014). However, Hackman and Wageman (1995) found that organizations frequently reinforce existing routines when initially confronted with evidence of their underperformance. Repenning (2000) and Schein (1996) found that unfreezing forces like fear only motivate organizational change when a credible signal exists for the perceived threat. Weeks (2004) found that shared readiness to change could still mask disagreements about the motivating factors - the why to change. At DevCo we found both a lack of shared readiness to change and disagreements about the factors motivating change. Of the three potential unfreezing forces that might motivate DevCo to implement the PIP (the market downturn, the mandate from MultiNat, and process data collected during the initial implementation), DevCo's management prioritized achieving the Silver certification by their declared deadline. The term "Lone Ranger," while used in jest, implied that DevCo's engineers were unwilling participants in the PIP activities. The request to sacrifice vacation implied negative consequences for missing the deadline rather than a shared 
commitment to meet a goal. The mandatory implementation of the PIP as a management priority, without corresponding effort to articulate it as an employee priority, leads to our first proposition:

Proposition 1: A mandatory PIP implementation will be less effective when conflicting interpretations of environmental signals diminish shared urgency to change.

While fairly general as stated, this proposition portends several more-specific research questions for future work. What role does context play in contributing to conflicting interpretations? Are environmental signals interpreted consistently in some contexts and inconsistently in others, such as PD? If so, which characteristics of different contexts contribute to this inconsistency? What actions are needed to build shared urgency to change in the presence of multiple interpretations? Is it possible to operationalize the construct of shared urgency (e.g., via consensus analysis or mental models) and thereby identify both barriers and opportunities for creating readiness to change? Is there a threshold of shared urgency that provides "good enough" unfreezing for an organization to proceed with its change?

\subsubsection{Inadequate PIP Tools did not Accurately Measure Operational Complexity}

Melnyk et al.'s (2010) study of an organization seeking to change from standardized production to radical innovation found that hidden causal paths from metrics to behaviors can create differences between the desired outcome (radical innovation) and the realized outcome (maintaining the status quo). Our data from DevCo extend these findings by showing that the absence of feedback paths from behavioral outcomes to the driving metrics limits an organization's ability to unfreeze. DevCo's PIP assumed that PD work could be measured as a single, linear path from inputs to outcomes (between stages 5 [Process Capability] and 7 [Know-why] in Bohn's (1994) typology of knowledge stages). Our data showed that DevCo's engineers did not experience their work as a linear process with immediate, direct impacts. That is consistent with findings from PIP deployment in other knowledge work contexts (Staats et al., 2011). In contrast with directly observable, standardized production contexts, the impact of non-programmed and innovative work is distributed through time and space across the organization. Coordination and control are problematic, because multiple parties receive information and make decisions, and system boundaries vary depending on the topic under consideration (Weick, 2001). Activities such as modeling processes, determining causes and effects, identifying sources of variation, and determining process failure modes all become more challenging in this context (Browning, 2003; Browning et al., 2006).

Due to this operational complexity, DevCo's engineers did not understand how the impacts of their work was felt by other departments. They interpreted findings from their own data collection in ways that protected themselves rather than capitalized on potential opportunities to change. The result was inhibited learning (Argyris, 1994) due to the disagreement about the Engineering organization's current (unmeasured) state and need to change, and thus a lack of consensus about whether the collected data could or should be used to identify a desirable future state. Hence, we propose that: 
Proposition 2: If the tools used to gather data do not identify clear and adequate gaps between the current and the desired states, then the mandatory PIP implementation will be less effective.

P2 suggests that some typical PIP tools may need further development when transferred to PD contexts, or that different tools (that model the network of PD tasks as a complex system) may be more appropriate. Further research could explore several lines of questioning. For example, are tools that model and measure a PD process as a linear path adequate, if the process and environment are mapped at the right level of detail? Or, are process modeling tools that convey linear paths inherently unsuitable for PD environments (where knowledge might only be between stages 2 [Awareness] and 4 [Control of the mean] in Bohn's typology), and therefore different tools and/or visual displays are needed? Are particular types of data more or less vulnerable to the inadequacies seen at DevCo (e.g., can some PIP tools be directly transferred while others may need to be contextualized)?

\subsection{Implications Regarding Adoption of the Change}

\subsubsection{A Barrier: Problematic PIP Metaphors}

Armenakis (1999:100) identified three reasons for organizational members to adopt a change and exhibit its associated behaviors: (1) to gain reward or avoid punishment; (2) to form a desired relationship with an individual, work group, supervisor, or the organization; (3) to internalize a behavior they believe is intrinsically appealing and proper. Symbols and metaphors affect this adoption because they can merge rational and irrational aspects of a change experience (either the message or the response) (Fox and Amichai-Hamburger (2001). Specifically, a well-designed metaphor can be an efficient mechanism to transfer both a set of practices and their associated meanings from one context to another. Metaphors thus impact the ability of an organization to transfer PIP practices from one location to another without consuming substantial amounts of time and resources (what Szulanski (1996, 2000) and Danese et al. (2017) called the stickiness of best practices).

As discussed in Section 4.2.2, the OS metaphor conveyed a set of PIP practices and meanings that MultiNat's PIP architects found beneficial (because it identified behaviors associated with consistency by making tacit knowledge explicit). In contrast, DevCo's engineers did not find the practices and meanings of the OS metaphor beneficial (even though they acknowledged that some elements of behavior advocated by the PIP were useful, such as ensuring repeatable outputs from individual tasks). DevCo's engineers interpreted the OS metaphor in their own way. They did not believe that codifying best practices was desirable (our data shows they believed the opposite). The OS metaphor did not have its desired positive effect, because MultiNat's PIP architects did not appreciate the unintended consequences of these divergent interpretations, nor did they allocate the amount of resources required to ensure that their intended interpretation transferred to DevCo. This leads us to propose:

Proposition 3: PIP metaphors that are problematic (because their meaning is not shared or because 
conveying their intended meaning consumes unplanned resources) will diminish the appropriateness of the change message, thereby making PIP implementation less effective.

Although P3 is likely to generalize beyond a PD context, our evidence from DevCo indicated that the context mattered in the sense that engineers seemed particularly likely to identify alternative interpretations for the OS symbol. That is, the context is likely to matter greatly in the determination of whether or not workers share a symbol's interpretation. Further research could explore the role of symbols specifically related to PIP deployment. For example, could a metaphor like the OS be used more effectively in nonengineering contexts? What characteristics contribute to symbols having shared levels of motivational power across the front and back stages? If individuals agree that some form of change is needed but disagree with the specific change being proposed (Armenakis and Harris, 2002:170), can metaphors be used to negotiate consensus about what constitutes an appropriate change?

\subsubsection{An Opportunity: Using the PIP to Develop Flexible Routines}

By defining the PIP as its OS, MultiNat's PIP architects sought strong embeddedness (HowardGrenville, 2005) of the PIP's principles. This meant the PIP should contain significant and consequential overlap with existing structures and expectations, that there would be reinforcing artifacts, and that its use would become increasingly pervasive. In other words, the organizational behaviors would be guided by prescribed tools that enabled DevCo to meet the PIP's certification criteria. Therefore, the PIP sought to establish a strong causal path from its certification outcomes through its prescribed tools to the expected behaviors.

We found that the PIP implementation did not achieve strong embeddedness at DevCo. Nevertheless, our data showed that DevCo's engineers were interested in changing how they performed their work, and that they acknowledged the potential of PIP principles to help them change. In their studies of ambivalence, Meyerson (2003; 2001) and Meyerson and Scully (1995) found that many individuals saw flaws in both the status quo and the mandated change initiative. They suggested that feedback from these individuals could identify previously overlooked causal paths that would enable the organization to change more effectively. Using such feedback to modify tools and patterns of action, as our data suggested DevCo had the potential to do, corresponds with weakly embedded routines (Howard-Grenville, 2005). Rather than being deployed solely via the prescribed causal paths associated with strong embeddedness, weakly embedded routines exist in the presence of competing artifacts and expectations, can be relatively easily adapted to new uses, and simultaneously employ multiple variants. The construct of weak embeddedness supports findings by Staats et al. (2011) regarding the limited value of high task specificity when implementing Lean in knowledge work contexts. It suggests that a PIP architecture should evolve through its implementation in similar ways to how a product architecture evolves through the PD lifecycle. We summarize the benefits of weak embeddedness as: 
Proposition 4: Planned flexibility to adopt PIP principles (weakly embedded routines) will improve employee views of their appropriateness, thereby increasing effectiveness of the PIP implementation.

Further research should unpack how weak embeddedness facilitates the transfer of PIP principles to new contexts. For example, some researchers have found change to be effective when middle managers bargain, negotiate, and reframe scope (Heyden et al., 2017; Huy, 2001). In contrast, Melnyk et al. (2010) found that too much flexibility for middle managers enabled preservation of the status quo, even when they agreed with the principles of the change. Thus, weak embeddedness needs to allow enough variation to flexibility to adapt routines, while at the same time not preserving the status quo (Austin, 1996). Interesting research questions to explore in this area include: What is the most effective way to connect PIP goals (means) with business needs and results (ends)? Can PIP goals be parsed across an organization in ways that consider contexts such as PD and their varied stages of knowledge (Bohn 1994)? What level of task specificity enables improvement without reducing individuals' abilities to perform their knowledge work effectively? Should managers seek a different level of embeddedness with PIP principles than with PIP tools? What oversight is needed to enable the bargaining and negotiation associated with weak embeddedness, while still ensuring the adoption of PIP principles and elevation from the status quo? Again, many of these questions can apply beyond a PD context, although the particulars of this context are likely to influence the answers strongly.

\subsubsection{Another Opportunity: Tailoring PIP Principles}

Initiatives seeking transformational change (i.e., strongly embedded, pervasively applied routines) view weak embeddedness as generating "organizational noise." Nevertheless, the construct provides opportunities for experiments with new ideas that can evolve into significant catalysts for change. Many of these experiments are conducted by individuals who identify flaws in their organizations' arguments and rhetoric for both change and maintaining the status quo (Meyerson, 2003; Meyerson, 2001; Meyerson and Scully, 1995). When transferring PIP principles to PD contexts, these experiments can provide important insights about implementation progress. For example, the guidance material for DevCo's PIP audits emphasized principles influenced by areas of repeatable, high-volume production and transactional environments. This is consistent with the heritage of the PIP's Lean tools and practices, as well as its original context at MultiNat. Meanwhile, MultiNat's PIP architects acknowledged the desire to manage information flow and encourage creativity, albeit generally in terms of future improvements to the PIP documentation and guidance. Moreover, our data suggested that DevCo's engineers believed that removing waste could help them demonstrate the skilled innovation that they felt the recently cancelled contracts had called into question. Similar to findings by Victor et al. (2000) and Staats et al. (2011), we expect that tailoring PIP principles to effectively integrate these kinds of overlapping interests would be associated 
with more reliable team performance, improved problem identification and resolution, less avoidance of PIP activities, shorter lead times to implement improvement ideas, and more widespread adoption of PIP activities (as opposed to participation being limited to specialists and/or managers).

Proposition 5: Tailoring PIP principles to new contexts (such as PD) will improve adoption and increase effectiveness of the PIP implementation.

Similar to the approach suggested by Browning and Sanders (2012), P5 reconceptualizes the construct of PIP scope away from off-the-shelf practices ("It worked there, so do it here") toward contextualization of underlying principles. This is relevant for both broadly determining the appropriate amount of flexibility in PIP implementation (e.g., balancing strong and weak embeddedness) and more specifically determining how to manage flexibility when transferring particular practices. In the first instance, there is much to be leveraged from OM learning about adapting project management tools to different PD projects and organizational contexts (e.g., Chandrasekaran et al., 2015; Pich et al., 2002). Sting et al. (2015) demonstrated the second instance when adapting rapid escalation of problems from the hierarchical responsibility of Andon systems in Lean manufacturing contexts to team-oriented problem solving in PD.

Future research could explore the application of continuous improvement (CI) principles to PD work that involves "situated knowing" (Blackler, 1995). Specific areas could include, e.g.: the tradeoffs between formalization and abstraction that are needed to achieve both flexibility and embeddedness, the characteristics of "task switching" between CI and knowledge work tasks, the environmental cues that enable switching (specifically when dealing with attributes of operational complexity such as low task specificity, work outputs separated in time and space, and architectural ambiguity), and the definition of PD job roles that enable such switching. Further research is also needed regarding the factors associated with the method for and optimal amount of PIP tailoring, customization, and contextualization.

\subsection{Re-freezing: Implications Regarding Institutionalization of the Change}

\subsubsection{Limits of Symbolic Compliance: Distant Benefits and Empty Milestone Compliance}

According to Reger et al. (1994), employees will not accept a change message if they believe it is unrealistic (high stress about the change) or unnecessary (high inertia to maintain the status quo). Section 4.2.1 discusses these dynamics at DevCo during the Silver PIP implementation. However, as discussed in Section 4.2.2, DevCo's engineers were willing to adopt the PIP principles, albeit not always in the forms presented during the Silver implementation. This suggests that the potential for commitment to the PIP's underlying principles was not articulated during the Silver implementation. Although not required for Silver, the criteria to reach Gold included requirements to demonstrate measurable commitment. (The PIP architects frequently discussed the exact measure to use; they recognized it was not straightforward.) Thus, DevCo's emphasis on implementing the PIP as an act of symbolic compliance to meet external milestones, focusing only on long-term benefits, (1) created disillusion due to the perceived lack of substantive change, 
(2) neglected feedback about how to institutionalize the PIP effectively in DevCo's context, and (3) missed an opportunity to nurture the commitment that was required for the Gold phase of implementation. These findings lead to our next propositions:

Proposition 6 : Emphasizing long-term benefits (without short-term "quick wins") creates perceptions of gaps between symbolic and substantive success and reduces personal benefit, thereby hindering the institutionalization of PIP principles and reducing PIP effectiveness.

Proposition 7: Mandatory PIP implementation that emphasizes achieving externally imposed deadlines and milestones will limit employees' commitment to its principles, thereby hindering the institutionalization of PIP principles and reducing PIP effectiveness.

P6 and P7 show how messages about the PIP implementation from the PIP architects contributed to both stress and indifference for employees, thus further hindering the transition from adoption to institutionalization. Future work in this area could explore at least two themes. First, what factors contribute to receiving a PIP's change message with stress and/or indifference? Are these factors related to PIP particular contexts? Like our discussion about the OS metaphor with P3, are there specific characteristics of PD environments (e.g., operational complexity, non-obvious/indirect causal paths, or longer time lags between causes and effects) that make them particularly problematic? Second, is it possible for change agents to manage messages about PIP implementation in PD contexts more effectively? What combination of messages is required to maintain focus on a long-term goal without disregarding near (in time and space) changes that represent progress towards the desired future state? Is there a combination of messages that can help employees internalize the new behaviors instead of displaying them simply to gain reward or avoid punishment? Assuming that perceived gaps between symbolic and substantive change can be reduced but never eliminated, when does a gap become "small enough" to facilitate institutionalization of the adopted change? Are there more or less effective ways to apply limited resources toward reducing the gap when PIPs are being coercively implemented under external pressures (such as MultiNat's mandate)?

\subsubsection{Limits of Grassroots Adoption}

DevCo could have organically implemented the PIP under two conditions. First, the PIP needed to be strongly embedded so that there was a clear causal path from the stated metric (Silver Certification with adoption of the PIP's tools) to the associated behavior of using the tools. Second, the awareness of future benefits from the PIP had to convince DevCo's employees to adopt new behavior (Bernard (2002) called this the educational model of social change). These conditions would allow deployment of the PIP under the premise that requiring extra effort in the short term (e.g., during the Silver Implementation), would yield tangible benefits that reinforced it. (Repenning and Sterman (2001) called this working smarter.) Indeed, DevCo frequently used the anticipated cost savings from more efficient operations to justify the lack of further budget for PIP implementation. 
We found that DevCo did not meet these two conditions. DevCo's emphasis on long-term benefits did not identify the specific, short-term benefits ("quick wins") expected from the Silver implementation. DevCo's engineers interpreted the data collected using the PIP's tools as a justification to maintain the status quo (P2). The OS metaphor did not generate enthusiasm about adopting the PIP's tools and behaviors (P3). These results confirm other research findings that re-freezing to a new status quo will not occur without adequate resources (Armenakis et al., 1999). This discredits the assumptions behind resource allocation decisions for DevCo's PIP implementation and probes the conditions under which working smarter (for free) yields sufficient benefits to gain traction for institutionalizing a change. DevCo invested enough in awareness of the PIP deadlines to achieve symbolic success with the Silver Implementation. Those resources were insufficient for DevCo's engineers to internalize the PIP principles and institutionalize them with substantive new behavior. These findings confirm Bernard's (2002) assertion that the educational model of social change can be effective when the targeted behavior exists at superstructural levels of society (e.g., changing brand preferences) but tends to be less effective when the targeted behavior is rooted in the structure or infrastructure of a group. The desire that the PIP be a grassroots initiative, coupled with the assumptions of strong embeddedness, actually hindered DevCo's ability to discuss the need for additional resources for PIP implementation. This leads to our final proposition.

Proposition 8: Relying on grassroots adoption of a mandatory PIP leads to inadequate resources for PIP institutionalization, thereby limiting PIP effectiveness.

This general proposition prompts further, more specific research. At DevCo we discovered several structural indicators that the resources applied to generate awareness of the PIP during the Silver Implementation did not harness the interest of engineers in actually adopting the PIP principles: the inadequacy of the PIP tools (poorly suited for DevCo's PD context), the need for weak embeddedness (a factor of DevCo's PD context), and the problematic OS metaphor (a factor of the mental models held by DevCo's engineers). Are there other circumstances under which the conditions of strong embeddedness and the educational model of social change do not apply for PIP implementation? Under these circumstances, what strategy should managers use to allocate resources for awareness, training, and assessment to institutionalize a work smarter approach? Given that the ideal level of resources is rarely available, how do decision makers satisfice to match the available resources with the most important factors for PIP deployment?

\section{Conclusion}

\subsection{Implications for Research and Practice}

Both the academic and practitioner literature have refined the characteristics of successful PIP implementation in manufacturing contexts. Both sets of literature agree that a successful PIP implementation will institutionalize new practices. However, neither body of literature rigorously 
articulates the challenges of transferring PIP principles to a PD context. Due to this gap in understanding, PIP implementations in PD have encountered problems that prevent them from achieving their intended benefits. Our study addresses this practical challenge by deeply exploring DevCo's PIP implementation in light of organizational change theory. We ground our empirical observations with predictions from existing theory (Colquitt and Zapata-Phelan, 2007) by drawing from OM-centric literature about PIP scope and context (Sections 2.1 and 2.2) and from extra-OM literature about change implementation (Section 2.3).

The findings in this paper elaborate two main areas of theory about PIP implementation and organizational change: (1) guiding the transfer of PIP principles (e.g., Lean and/or Six Sigma) from a repetitive production context to that of PD and (2) guiding the process of PIP implementation by clarifying sources of (and hopefully ways to reduce) the gap between symbolic and substantive success. The resulting propositions, summarized in Table 7, provide several insights on the research question of how to implement PIPs reliably when reconceptualizing the principles in new contexts.

Our examination of change agent (MultiNat's PIP council and DevCo's management) and employee (DevCo's engineers) data sheds specific light on the underlying organizational context and "previously unexplored relationships" (Colquitt and Zapata-Phelan, 2007) that present opportunities and hazards for effective PIP implementation. These findings identify some of the characteristics that contributed to a lack of substantive change during DevCo's PIP Silver implementation. We "re-conceptualize the existing construct" (Colquitt and Zapata-Phelan, 2007) of PIP scope by showing how the goal of continuous improvement can be tailored to improve knowledge work in PD contexts. Specifically, DevCo's engineers identified a narrow "change acceptance zone" (Reger et al., 1994) for adopting the PIP principles-a tailored, weakly embedded program that continuously improves their work without seeking standardized production of its tasks. These findings show how a PIP can amplify creativity in high-uncertainty conditions by enhancing the flow of value-adding information within and among PD teams. Re-casting a PIP with this view enables an organization to sustain change and progress while it adapts its PD activities to evolving product and market conditions.

Table 7: Findings and Implications from DevCo's PIP Implementation

\begin{tabular}{lll}
\hline Lewin Element & Case Study Findings from DevCo (Section 4) & $\begin{array}{c}\text { Managerial Implications for Transferring PIPs } \\
\text { to New Contexts }\end{array}$ \\
\hline & - $\begin{array}{l}\text { Management priorities to comply with MultiNat's } \\
\text { PIP implementation directive were not shared by } \\
\text { the employees. }\end{array}$ & $\begin{array}{l}\text { Change agents should ensure that there are } \\
\text { shared interpretations of urgency to change (P1). }\end{array}$ \\
$\begin{array}{l}\text { Unfreeze: } \\
\begin{array}{l}\text { Remove the } \\
\text { restraining } \\
\text { forces that } \\
\text { maintain the } \\
\text { status quo }\end{array}\end{array}$ & $\begin{array}{l}\text { Employees had conflicting interpretations of } \\
\text { DevCo's market pressures. }\end{array}$ & $\begin{array}{l}\text { PIP architects should understand the risk that } \\
\text { tools are not used in ways which produce data } \\
\text { that creates a credible discrepancy between the } \\
\text { current and desired future state (P2). }\end{array}$ \\
& $\begin{array}{l}\text { PIP data did not generate the expected learning } \\
\text { recognized by the I-P-O-based tools. }\end{array}$ &
\end{tabular}




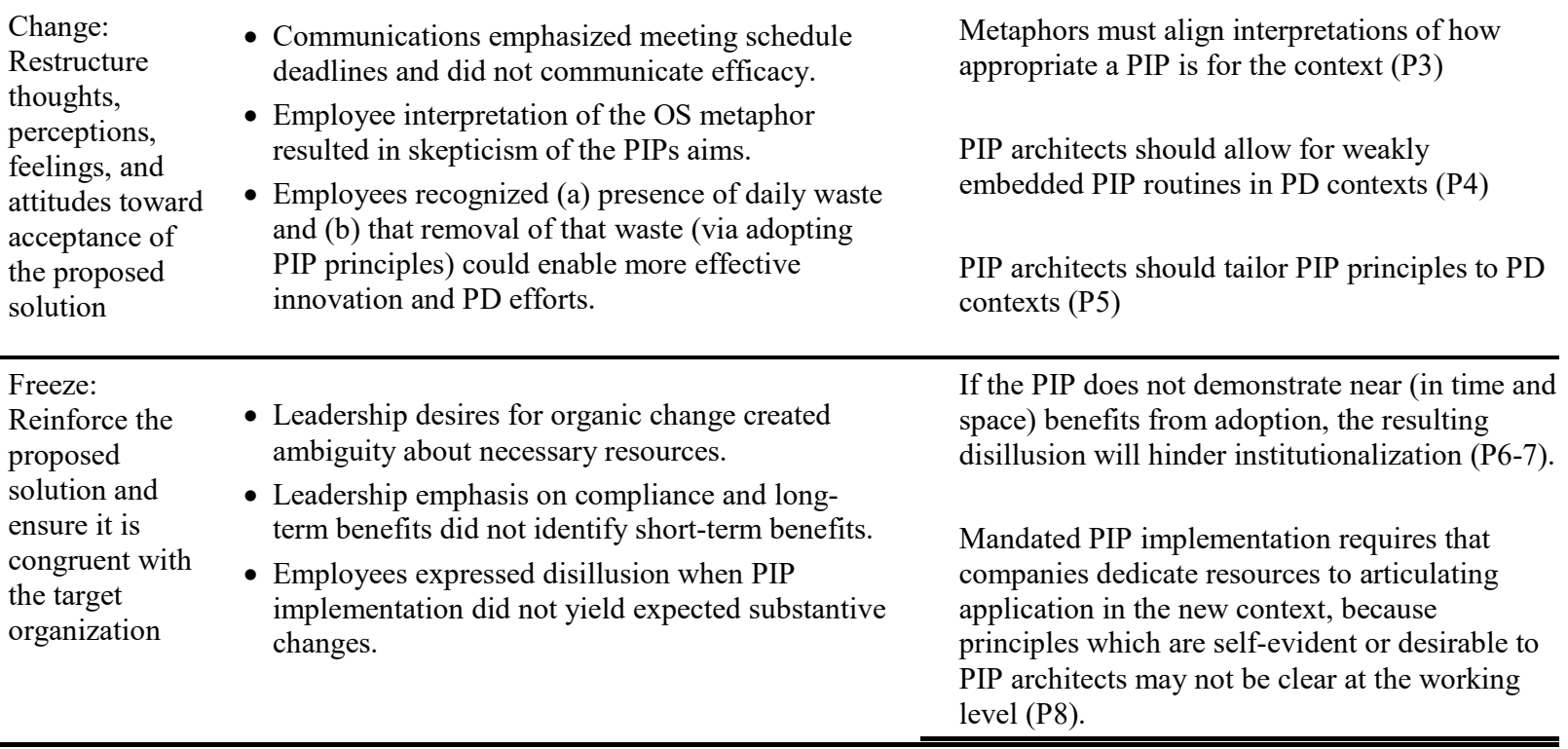

\subsection{Limitations and Final Thoughts}

Like Aime et al. (2014), our study reveals and proposes phenomena of interest rather than testing formal hypotheses. This imposes limitations. First, our longitudinal study draws from a single, clinical study of DevCo's experience. Like Bhakoo and Choi (2013), we address this by (1) not making overarching generalizations, (2) seeking breadth in our data collection at DevCo (to support internal validity), and (3) grounding our findings with pertinent literature (to elaborate theory in externally valid ways). Second, our study focuses on the process of PIP implementation rather than the characteristics of mature PIPs. We concluded our two-year study at DevCo after the Gold Planning phase due to a variety of factors that prevented further data collection (the first author changed roles, DevCo was restructured with some of its product lines moving to other MultiNat divisions, and MultiNat eventually sold DevCo to another company). After many problematic turns, it is possible that companies like DevCo could eventually exhibit the characteristics associated with mature PIP implementation. However, despite not knowing whether DevCo's PIP implementation ultimately achieved substantive success, we believe the findings from the Silver implementation are relevant for the broader OM community, which experiences similar mandates for compliance with prescribed best practices. Third, our study shows that context matters in the transfer of PIP principles, and that aspects of implementation such as metaphors and tools interact with the stickiness of knowledge in these principles. This opens the door for future research on how context and stickiness manifest in the transfer of PIP principles and (more importantly) what OM practitioners should do differently with this knowledge.

Our results help both researchers and practitioners explore the question of how to sustainably transfer PIP principles to PD contexts. Based solely on our findings in Section 4, we cannot conclude that DevCo's 
attempt to transfer the PIP from the manufacturing context of MultiNat's other divisions to its own PD context was unsuccessful. Instead, like the findings of Canato and colleagues (Canato and Ravasi, 2014; Canato et al., 2013) regarding the adoption of Six Sigma at 3M, our findings show opportunities to adapt PIP implementation to a PD context, as well as potential challenges with implementing a PIP in a manner that yields substantive organizational change in much broader contexts. Observing how DevCo responded to the PIP implementation provided "deeper understanding of how success might ultimately be achieved" (Melnyk et al., 2010:570). The resulting propositions enable OM researchers and practitioners to "direct their efforts at understanding why and how these [factors associated with effective PIP implementation] came to be" (Hambrick, 2007).

These findings may not seem completely surprising to someone well-versed in the challenges of organizational change theory. However, this does not describe most OM researchers (and certainly not practitioners). And while many of our findings will resonate with practitioners' experiences and consultants' heuristics, the theory of PIP implementation has not yet been well developed by scholars. There is value to both $\mathrm{OM}$ researchers and practitioners in integrating several strands of management theory and applying them to the specific challenges of transferring PIPs to PD contexts. This is relevant for the specific instance of Lean and Six Sigma, from which we derived our data at DevCo, as well as other PIP constructs like Agile and Scrum. In general, we provide further evidence that transferring PIPs to new contexts is not simple and intuitive, and that "one size" does not fit all situations. Viewing process improvement in PD contexts as an issue of organizational change begins the journey towards an integrated approach with both challenges and opportunities.

\section{References}

Adler, P.S., Benner, M.J., Brunner, D.J., MacDuffie, J.P., Osono, E., Staats, B.R., Takeuchi, H., Tushman, M.L., Winter, S.G., 2009. Perspectives on the Productivity Dilemma. Journal of Operations Management 27, 99-113

Adler, P.S., Clark, K.B., 1991. Behind the Learning Curve: A Sketch of the Learning Process. Management Science 37, 267-281

Ahire, S.L., Dreyfus, P., 2000. The Impact of Design Management and Process Management on Quality: An Empirical Investigation. Journal of Operations Management 18, 549-575

Aime, F., Humphrey, S., Derue, D.S., Paul, J.B., 2014. The Riddle of Heterarchy: Power Transitions in Cross-Functional Teams. Academy of Management Journal 57, 327-352

Anand, G., Ward, P.T., Tatikonda, M.V., 2010. Role of explicit and tacit knowledge in Six Sigma projects: An empirical examination of differential project success. Journal of Operations Management 28, 303-315

Ansari, S., Fiss, P.C., Zajac, E.J., 2010. Made to Fit: How Practices Vary as They Diffuse. Academy of Management Review 35, 67-92

Argyris, C., 1994. Good Communication that Blocks Learning. Harvard Business Review, 77-85

Arlbjørn, J.S., Vagn Freytag, P., 2013. Evidence of lean: a review of international peer-reviewed journal articles. European Business Review 25, 174-205

Armenakis, A.A., Harris, S.G., 2002. Crafting a Change Message to Create Transformational Readiness. Journal of Organizational Change Management 15, 169-183

Armenakis, A.A., Harris, S.G., Field, H.S., 1999. Making Change Permanent: A Model for 
Institutionalizing Change Interventions. Research In Organizational Change and Development 12, 97-128 Armenakis, A.A., Harris, S.G., Mossholder, K., 1993. Creating Readiness for Organizational Change. Human Relations 46, 1-23

Austin, R.B., 1996. Measuring and Managing Performance in Organizations. Dorset House, New York, NY Ayres, L., Kavanaugh, K., Knafl, K.A., 2003. Within-Case and Across-Case Approaches to Qualitative Data Analysis. Qualitative Health Research 13, 871-883

Baba, M.L., 1995. The Cultural Ecology of the Corporation: Explaining Diversity in Work Group Responses to Organizational Transformation. Journal of Applied Behavioral Science 31, 202-233

Barley, S.R., Kunda, G., 2001. Bringing Work Back In. Organization Science 12, 76-95

Barratt, M., Choi, T.Y., Li, M., 2011. Qualitative case studies in operations management: Trends, research outcomes, and future research implications. Journal of Operations Management 29, 329-342

Beer, M., 2003. Why Total Quality Management Programs Do Not Persist: The Role of Management Quality and Implications for Leading a TQM Transformation. Decision Sciences 34, 623-641

Bernard, H.R., 2002. Research Methods In Anthropology. AltaMira Press, Walnut Creek, CA

Bhakoo, V., Choi, T.Y., 2013. The iron cage exposed: Institutional pressures and heterogeneity across the healthcare supply chain. Journal of Operations Management 31, 432-449

Birkinshaw, J., Hamel, G., Mol, M.J., 2008. Management Innovation. Academy of Management Review 33, 825-845

Black, S.A., Porter, L.J., 1996. Identification of the Critical Factors of TQM. Decision Sciences 27, 1-21

Blackler, F., 1995. Knowledge, knowledge work and organizations: an overview and interpretation. Organization Science 16, 1021-1046

Bohn, R.E., 1994. Measuring and Managing Technological Knowledge. Sloan Management Review 36, 61-73

Boothroyd, G., Dewhurst, P., Knight, W., 1994. Product Design for Manufacture and Asembly. Marcel Dekker, New York, NY

Browning, T.R., 2003. On Customer Value and Improvement in Product Development Processes. Systems Engineering 6, 49-61

Browning, T.R., Fricke, E., Negele, H., 2006. Key Concepts in Modeling Product Development Processes. Systems Engineering 9, 104-128

Browning, T.R., Heath, R.D., 2009. Reconceptualizing the Effect of Lean on Production Costs with Evidence from the F-22 Program. Journal of Operations Management 27, 23-44

Browning, T.R., Sanders, N.R., 2012. Can Innovation Be Lean? California Management Review 54, 5-19 Canato, A., Ravasi, D., 2014. Managing long-lasting cultural changes. Organizational Dynamics 44, 75-82 Canato, A., Ravasi, D., Phillips, N., 2013. Coerced Practice Implementation in Cases of Low Cultural Fit: Cultural Change and Practice Adaptation During the Implementation of Six Sigma at 3M. Academy of Management Journal 56, 1724-1753

Chandrasekaran, A., Linderman, K., Schroeder, R.G., 2015. The role of project and organizational context in managing high-tech R\&D projects. Production and Operations Management 24, 560-586

Chen, J., Damanpour, F., Reilly, R.R., 2010. Understanding Antecedents of New Product Development Speed: A Meta-analysis. Journal of Operations Management 28, 17-33

Choo, A.S., Linderman, K.W., Schroeder, R.G., 2007. Method and Psychological Effects on Learning Behaviors and Knowledge Creation in Quality Improvement Projects. Management Science 53, 437-450

Clausing, D., 1994. Total Quality Development: A Step-by-Step Guide to World-Class Concurrent Engineering. ASME Press, New York, NY

Coghlan, D., 2009. Toward a Philosophy of Clinical Inquiry/Research. The Journal of Applied Behavioral Science 45, 106-121

Collins, S.T., 2009. Wading and Jumping into a New Job: Exploring Dynamics of Knowledge Flow for Systems Engineers. Human Organization 68, 194-205

Collins, S.T., Bradley, J., Yassine, A., 2010. Analyzing Product Development Task Networks to Examine Organizational Change. IEEE Transactions on Engineering Management 57, 513-525

Collins, S.T., Yassine, A., Bogarti, S., 2009. Evaluating Product Development Systems Using Network 
Analysis. Systems Engineering 12, 55-68

Colquitt, J.A., Zapata-Phelan, C.P., 2007. Trends in Theory Building and Theory Testing: A Five-Decade Study of the Academy of Management Journal. Academy of Management Journal 50, 1281-1303

Cooper, R.G., Edgett, S.J., Kleinschmidt, E.J., 2002. Optimizing the Stage-Gate Process: What Best Practice Companies Do - II. Research Technology Management 45, 21-27

Cooper, R.G., Kleinschmidt, E.J., 1993. Stage Gate Systems for New Product Success. Marketing Management 1, 10-29

Dahlgaard, J.J., Dahlgaard-Park, S.M., 2006. Lean production, six sigma quality, TQM and company culture. The TQM Magazine 18, 263-281

Damanpour, F., 2001. The Dynamics ofthe Adoption of Product and Process Innovations in Organizations. Journal of Management Studies 38, 45-65

Danese, P., Romano, P., Boscari, S., 2017. The transfer process of lean practices in multi-plant companies. International Journal of Operations \& Production Management 37, 468-488

Davenport, T.H., Jarvenpaa, S.L., Beers, M.C., 1996. Improving knowledge work processes. Sloan Management Review 37, 53+

Dutton, J.E., Ashford, S.J., O'Neill, R.M., Lawrence, K.A., 2001. Moves That Matter: Issue Selling And Organizational Change. Academy of Management Journal 44, 716-736

Eidt, C.M., 1992. Applying Quality to R\&D Means 'Learn-as-you-go'. Research Technology Management 35, 24-31

Eisenhardt, K.M., 1989. Building Theories from Case Study Research. Academy of Management Review $14,532-550$

Eisenhardt, K.M., Graebner, M.E., 2007. Theory Building from Cases: Opportunities and Challenges. Academy of Management Journal 50, 25-32

Emerson, R.M., Fretz, R.I., Shaw, L.L., 1995. Writing Ethnographic Fieldnotes. The University of Chicago Press, Chicago, IL

Flynn, B.B., Sakakibara, S., Schroeder, R.G., Bates, K.A., Flynn, E.J., 1990. Empirical Research Methods in Operations Management. Journal of Operations Management 9, 250-284

Fox, S., Amichai-Hamburger, Y., 2001. The Power of Emotional Appeals in Promoting Organizational Change. Academy of Management Executive 15, 84-95

Frohman, A.L., 1997. Igniting Organizational Change From Below: The Power Of Personal Initiative. Organizational Dynamics 25, 39-53

Furterera, S., Elshennawy, A.K., 2005. Implementation of TQM and Lean Six Sigma Tools in Local Government: A Framework and a Case Study. Total Quality Management \& Business Excellence 16, 11791191

Glaser, B.G., Strauss, A.L., 1967. The Discovery of Grounded Theory: Strategies for Qualitative Research. Aldine Publishing Company, Chicago

Groop, J., Ketokivi, M., Gupta, M., Holmstrom, J., 2017. Improving home care: Knowledge creation through engagement and design. Journal of Operations Management 53-56, 9-22

Guest, G., Bunce, A., Johnsen, L., 2006. How Many Interviews are Enough? An Experiment with Data Saturation and Variability. Field Methods 18, 59-82

Hackman, J.R., Wageman, R., 1995. Total Quality Management: Empirical, Conceptual, and Practical Issues. Administrative Science Quarterly 40, 309-342

Hambrick, D.C., 2007. The Field of Management's Devotion to Theory: Too Much of a Good Thing? Academy of Management Journal 50, 1346-1352

Handfield, R.B., Melnyk, S.A., 1998. The Scientific Theory-Building Process: A Primer using the Case of TQM. Journal of Operations Management 16, 321-339

Handwerker, W.P., 2001. Quick Ethnography. AltaMira Press, Walnut Creek, CA

Henderson, R., Del Alamo, J., Becker, T., Lawton, J., Moran, P., Shapiro, S., 1998. The perils of excellence:

Barriers to effective process improvement in product-driven firms. Production and Operations Management 7, 2-18

Heyden, M.L.M., Fourne, S.P.L., Doene, B.A.S., Werkman, R., Ansari, S., 2017. Rethinking ‘Top-Do wn’ 
and 'Bottom -Up' Roles of Topand Middle Managers in Organizational Change:Implications for Employee Support. Journal of Management Studies 54, 961-985

Hines, P., Holweg, M., Rich, N., 2004. Learning to evolve: A review of contemporary lean thinking. International Journal of Operations \& Production Management 42, 994-1011

Hjort, H., Hananel, D., Lucas, D., 1991. Quality Functional Deployment and Integrated Product Development. Journal of Engineering Design 3, 17-29

Holmstrom, J., Ketokivi, M., Hameri, A., 2009. Bridging Practice and Theory: A Design Science Approach. Decision Sciences 40, 65-87

Holweg, M., 2007. The genealogy of lean production. Journal of Operations Management 25, 420-437

Howard-Grenville, J.A., 2005. The Persistence of Flexible Organizational Routines: The Role of Agency and Organizational Context. Organization Science 16, 618-636

Huy, Q.N., 2001. In Praise of Middle Managers. Harvard Business Review 79, $72-79$

Ilgen, D.R., Hollenbeck, J.R., Johnson, M., Jundt, D., 2005. Teams in Organizations: From Input-ProcessOutput Models to IMOI Models. Annual Review of Psychology 56, 517-543

Jadhav, J.R., Mantha, S.S., Rane, S.B., 2014. Exploring barriers in lean implementation. International Journal of Lean Six Sigma 5, 122-148

Jiao, H., Zhao, G., 2014. When will employees embrace managers' technological innovations? The mediating effects of employees' perceptions of fairness on their willingness to accept change and its legitimacy. Journal of Product Innovation Management 31, 780-798

Johnson, A., Swisher, B., 2003. How Six Sigma Improves R\&D. Research Technology Management 46, 12-15

Jones, E.C., Mellat Parast, M., Adams, S.G., 2010. A Framework for Effective Six Sigma Implementation. Total Quality Management 21, 415-424

Ketokivi, M., Choi, T.Y., 2014. Renaissance of case research as a scientific method. Journal of Operations Management 32, 232-240

Kilmann, R.H., Mitroff, I.I., 1979. Problem Defining And The Consulting/Intervention Process. California Management Review 21, 26-33

Kotter, J.P., 1996. Leading Change. Harvard Business School Press, Boston, MA

Kull, T.J., Narasimhan, R., Schroeder, R.G., 2012. Sustaining the Benefits of a Quality Initiative through Cooperative Values: A Longitudinal Study. Decision Sciences 43, 553-588

Kunda, G., Barley, S.R., Evans, J., 2002. Why do Contractors Contract? The Experience of Highly Skilled Technical Professionals in a Contingent Labor Market. Industrial and Labor Relations Review 55, 234-261 LaGanga, L.R., 2011. Lean service operations: Reflections and new directions for capacity expansion in outpatient clinics. Journal of Operations Management 29, 422-433

Langley, A., 1999. Strategies for Theorizing from Process Data. Academy of Management Review 24, 691710

Langley, A., Smallman, C., Tsoukas, H., Van de Ven, A.H., 2013. Process Studies of Change in Organization and Management: Unveiling Temporality, Activity, and Flow. Academy of Management Journal 56, 1-13

Levy, R.I., Hollan, D.W., 1998. Person-Centered Interviewing and Observation, In: Bernard, H.R. (Ed), Handbook of Methods in Cultural Anthropology. AltaMira Press, Walnut Creek, CA, pp. 333-364

Lewin, K., 1951. Field Theory in Social Science. Harper \& Row, New York, NY

Liker, J.K., Fruin, W.M., Adler, P.S., 1999. Bringing Japanese Management Systems to the United States: Transplantation or Transformation, In: Liker, J.K., Fruin, W.M., Adler, P.S. (Eds), Remade in America: Transplanting and Transforming Japanese Management Systems. Oxford University Press, Oxford, UK, pp. 3-35

Lillrank, P., 1995. The Transfer of Management Innovations from Japan. Organization Science 16, 971989

Lillrank, P., 2003. The Quality of Standard, Routine and Nonroutine Processes. Organization Science 24, 215-233

Linderman, K., Schroeder, R.G., Sanders, J., 2010. A Knowledge Framework Underlying Process 
Management. Decision Sciences 41, 689-719

Linderman, K.W., Schroeder, R.G., Zaheer, S., Choo, A.S., 2003. Six Sigma: A Goal-Theoretic Perspective. Journal of Operations Management 21, 193-203

Linderman, K.W., Schroeder, R.G., Zaheer, S., Liedtke, C., Choo, A.S., 2004. Integrating Quality Management Practices with Knowledge Creation Processes. Journal of Operations Management 22, 589607

Lok, J., De Rond, M., 2013. On the Plasticity of Institutions: Containing and Restoring Practice Breakdowns at the Cambridge University Boat Club. Academy of Management Journal 56, 185-207

March, J.G., Sproull, L.S., Tamuz, M., 1991. Learning from Samples of One or Fewer. Organization Science 2, 1-13

Mathieu, J.E., 2016. The Problem with [in] Management Theory. Journal of Organizational Behavior forthcoming

McCutcheon, D.M., Meredith, J.R., 1993. Conducting Case Study Research in Operations Management. Journal of Operations Management 11, 239-256

McManus, H., Haggerty, A., Murman, E.M., 2007. Lean Engineering: A Framework for Doing the Right Job Right. Aeronautical Journal 111, 105-114

Melnyk, S.A., Hanson, J.D., Calantone, R.J., 2010. Hitting the Target but Missing the Point: Resolving the Paradox of Strategic Transition. Long Range Planning 43, 555-574

Meredith, J.R., 1998. Building Operations Management Theory through Case and Field Research. Journal of Operations Management 16, 441-454

Meyerson, D., 2003. Tempered Radicals: How Everyday Leaders Inspire Change At Work. Harvard Business School Press, Boston, MA

Meyerson, D.E., 2001. Radical Change, the Quiet Way. Harvard Business Review 79, 92-100

Meyerson, D.E., Scully, M.A., 1995. Tempered Radicalism and the Politics of Ambivalence and Change. Organization Science 6, 585-600

Mintzberg, H., 1979. An Emerging Strategy of 'Direct' Research. Administrative Science Quarterly 24, 582589

Murman, E.M., Allen, T., Bozdogan, K., Cutcher-Gershenfeld, J., McManus, H., Nightingale, D., Rebentisch, E., Shields, T., Stahl, F., Walton, M., Warmkessel, J., Weiss, S., Widnall, S., 2002. Lean Enterprise Value. Palgrave, New York

Naor, M., Goldstein, S.M., Linderman, K.W., Schroeder, R.G., 2008. The Role of Culture as Driver of Quality Management and Performance: Infrastructure Versus Core Quality Practices. Decision Sciences 39, 671-702

Netland, T.H., 2016. Critical Success Factors for Implementing Lean Production: the Effect of Contingencies. International Journal of Production Research 54, 2433-2448

Oppenheim, B.W., 2004. Lean Product Development Flow. Systems Engineering 7, 352-376

Pentland, B.T., Feldman, M.S., 2008. Designing Routines: On the folly of designing artifacts, while hoping for patterns of action. Information and Organization 18, 235-250

Pich, M.T., Loch, C.H., Meyer, A.D., 2002. On uncertainty, ambiguity, and complexity in project management. Management Science 48, 1008-1023

Pisani, M.J., Hayes, R., Kumar, A., Lepisto, L., 2009. Is Six Sigma Culture Bound? A Conceptual Model and Propositions for Further Inquiry. Total Quality Management 20, 1123-1137

Poppendieck, M., Poppendieck, T., 2003. Lean Software Development: An Agile Toolkit. Addison-Wesley, Upper Saddle River, NJ

Rafferty, A.E., Jimmieson, N.L., Armenakis, A.A., 2012. Change Readiness: A Multilevel Review. Journal of Management 39, 110-135

Reger, R.K., Gustafson, L.T., Demarie, S.M., Mullane, J.V., 1994. Reframing The Organization: Why Implementing Total Quality Is Easier Said Than Done. Academy of Management Review 19, 565-584

Repenning, N.P., 2000. Drive Out Fear (Unless You Can Drive It in): The Role of Agency and Job Security in Process Improvement. Management Science 46, 1385-1396

Repenning, N.P., Sterman, J.D., 2001. Nobody Ever Gets Credit for Fixing Problems that Never Happened: 
Creating and Sustaining Process Improvement. California Management Review 43, 64-88

Rerup, C., Feldman, M.S., 2011. Routines as a Source of Change in Organizational Schema: The Role of Trial-and-Error Learning. Academy of Management Journal 54, 577-610

Roemer, T.A., Ahmadi, R., 2010. Models for Concurrent Product and Process Design. European Journal of Operations Research 203, 601-613

Schein, E.R., 1987. The Clinical Perspective in Fieldwork. Sage Publications, Inc., Newbury Park, CA Schein, E.R., 1993. Legitimizing Clinical Research in the Study of Organizational Culture. Journal of Counseling and Development 71

Schein, E.R., 1996. Kurt Lewin's Change Theory in the Field and in the Classroom: Notes Toward a Model of Managed Learning. Reflections 9, 27-47

Schroeder, R.G., Linderman, K., Zhang, D., 2005. Evolution of Quality: First Fifty Issue of Production and Operations Management. Production and Operations Management 14, 468-481

Schroeder, R.G., Linderman, K.W., Liedtke, C., Choo, A.S., 2008. Six Sigma: Definition and Underlying Theory. Journal of Operations Management 26, 536-554

Sobek II, D.K., Ward, A.C., Liker, J.K., 1999. Toyota's Principles of Set-Based Concurrent Engineering. Sloan Management Review 40, 67-83

Sousa, R., Voss, C.A., 2002. Quality Management Re-Visited: A Reflective Review and Agenda for Future Research. Journal of Operations Management 20, 91-109

Sousa, R., Voss, C.A., 2008. Contingency Research in Operations Management Practices. Journal of Operations Management 26, 697-713

Spain, D.R., 1996. To Improve Quality in R\&D, Improve the Team Work Process. Research Technology Management 42-47

Staats, B.R., Brunner, D.J., Upton, D.M., 2011. Lean Principles, Learning, and Knowledge Work: Evidence from a Software Services Provider. Journal of Operations Management 29, 376-390

Sting, F.J., Loch, C.H., Stempfhuber, D., 2015. Accelerating projects by encouraging help. MIT Sloan Management Review 56, 33

Stuart, I., McCutcheon, D.M., Handfield, R., McLachlin, R., Sampson, D., 2002. Effective Case Research in Operations Management: A Process Perspective. Journal of Operations Management 20, 419-433

Suckley, L.J., Price, I., 2013. Exploring inter-departmental barriers between production and quality. Journal of Organizational Ethnography 2, 173-190

Sutton, R.I., Callahan, A.L., 1987. The Stigma of Bankruptcy: Spoiled Organizational Image and Its Management. Academy of Management Journal 30, 405-436

Swink, M., Jacobs, B.W., 2012. Six Sigma adoption: Operating performance impacts and contextual drivers of success. Journal of Operations Management 30, 437-453

Szulanski, G., 1996. Exploring Internal Stickiness: Impediments to the Transfer of Best Practice within the Firm. Strategic Management Journal 17, 27-43

Szulanski, G., 2000. The Process of Knowledge Transfer: A Diachronic Analysis of Stickiness. ORganizational Behavior and Human Decision Processes 82, 9-27

Van de Ven, A.H., 2007. Engaged Scholarship: A Guide for Organizational and Social Research. Oxford University Press, New York

Van Oorschot, K.E., Akkermans, H., Sengupta, K., Van Wassenhove, L.N., 2013. Anatomy of a decision Trap in Complex New Product Development Projects. Academy of Management Journal 56, 285-307

Victor, B., Boynton, A., Stephens-Jahng, T., 2000. The Effective Design of Work Under Total Quality Management. Organization Science 11, 102-117

Volberda, H.W., Van Den Bosch, F.A.J., Mihalache, O.R., 2014. Advancing Management Innovation: Synthesizing Processes, Levels of Analysis, and Change Agents. Organization Studies 35, 1245-1264

Weeks, J., 2004. Unpopular Culture. University of Chicago Press, Chicago, IL

Weick, K.E., 2001. Making Sense of the Organization. Blackwell Publishers, Inc, Malden, MA

Womack, J.P., Jones, D.T., 2003. Lean Thinking, Revised ed. Free Press, New York

Womack, J.P., Jones, D.T., Roos, D., 1990. The Machine that Changed the World. Rawson Associates, HarperCollins, New York, NY 
Yin, R.K., 2003. Case Study Research, 3rd edition. Sage, Newbury Park, CA

Yin, Y., Stecke, K.E., Swink, M., Kaku, I., 2017. Lessons from seru production on manufacturing competitively in a high cost environment. Journal of Operations Management 49-51, 67-76

Zbaracki, M.J., 1998. The Rhetoric and Reality of Total Quality Management. Administrative Science Quarterly 43, 602-636

Zhang, W., Hill, A.V., Gilbreath, G.H., 2011. A Research Agenda for Six Sigma Research. Quality Management Journal 18, 39-53

Zmud, R.W., 1984. An examination of "push-pull" theory applied to process innovation in knowledge work. Management Science 30, 727-738

$\mathrm{Zu}$, X., Fredendall, L.D., Douglas, T.J., 2008. The Evolving Theory of Quality Management: The Role of Six Sigma. Journal of Operations Management 26, 630-650

$\mathrm{Zu}, \mathrm{X}$., Robbins, T.L., Fredendall, L.D., 2009. Mapping the critical links between organizational culture and TQM/Six Sigma practices. International Journal of Production Economics 123, 86-106 